Other Project Team Member Organizations:

Euclid Heat Treating Co. 1408 East $222^{\text {nd }}$ Street Cleveland, Oh 44117

Summit Heat Treating Co. 336 Morgan Ave. Akron, Ohio 44309

General Aluminum Manufacturing Co. 1370 Chamberlain Blvd. Conneaut, Ohio 44030

Final Technical Report

\title{
Intensive Quenching Technology for Heat Treating and Forging Industries
}

DOE Award Number: DE-FC36-03ID 14463

Project Period: April 2003 - September 2005

Technical Point of Contact:

Dr. Michael A. Aronov, CEO

IQ Technologies, Inc.

Ph/Fax: (216) 381-8159

m.a.Aronov@sbcglobal.net

Recipient Organizations:

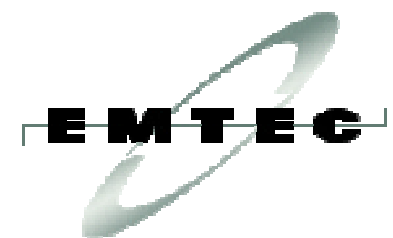

3155 Research Blvd. Dayton, Ohio 45420

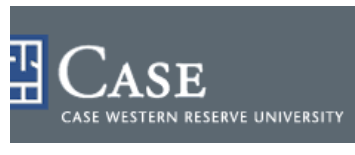

10900 Euclid Ave. Cleveland, Ohio 44106

\section{IQ 'Techuologies luc}

P.O. Box 1787

Akron, Ohio 44309

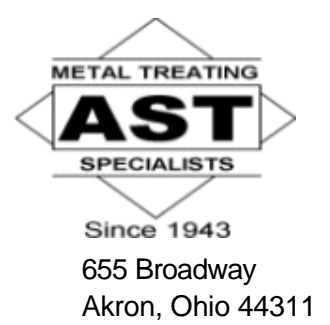




\section{Acknowledgment}

This report is based upon work supported by the U. S. Department of Energy under Award No. DE-FC36-03ID 14463

\section{Disclaimer}

Any findings, opinions, and conclusions or recommendations expressed in this report are those of the author(s) and do not necessarily reflect the views of the Department of Energy. 


\section{Table of Contents}

Executive Summary

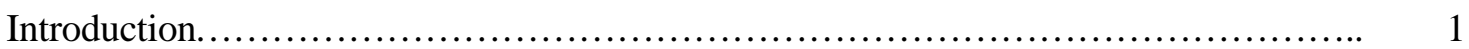

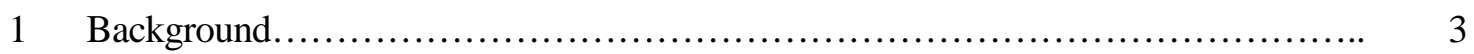

1.1 Basics of Intensive Quenching..................................... 3

1.2 Domestic and Worldwide Technology Status........................... 6

1.3 Why DOE Support Was Needed..................................... 7

2 Project Goal, Statement of Work and Team...................................... 8

2.1 Project Goal.................................................... 8

2.2 Statement of Objectives.......................................... 8

2.3 Project Team.................................................. 8

3 Improvement of Existing Intensive Quenching Process Capabilities................. 10

3.1 Modification of Production IQ Water Tank at Akron Steel Treating Co..... 10

3.2 Establishing of Center for Intensive Quenching......................... 11

3.2.1 Single Part Quenching IQ System....................... 11

3.2.2 Batch Quenching IQ System............................ 12

3.2.3 Continuous IQ System................................... 15

4 Demonstration and Validation of Intensive Quenching Technology................. 16

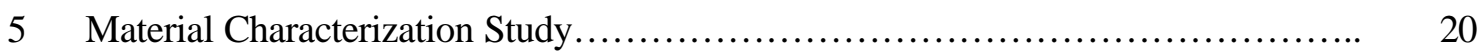

5.1 Material Characterization Study Procedure............................ 20

5.2 Improvement of Through-Hardening Steel Mechanical Properties........... 21

5.3 Improvement of Case Depth and Residual Surface Compressive Stresses for Carburized Steels............................................ 25

5.4 Improvement of Residual Stress Conditions for Through-Hardening 52100 Bearing Steel................................................ 27

5.5 Recommendations for Establishing New IQ Standards ..................... 29

6 Commercialization of Intensive Quenching Technology......................... 30

6.1 Introduction of IQ Process at Akron Steel Treating Co.................. 30

6.2 Introduction of IQ Process at Euclid Heat Treating Co................... 31

6.3 Role of Center for Intensive Quenching in IQ Process Commercialization... 33

$7 \quad$ Project Economic, Energy and Environmental Benefits Evaluation................... 35

$\begin{array}{lll}\text { 7.1 Savings Due Complete Elimination or Reduction of Carburization Cycle... } 35 & 35\end{array}$

7.1.1 Savings Per One Heat-Treating Furnace.................... 35

7.1.2 Savings for Heat-Treating Industry....................... 36

7.2 Savings Due to Part Weight reduction..................................... 38

7.3 Summary of Benefits Provided by IQ Process......................... 39

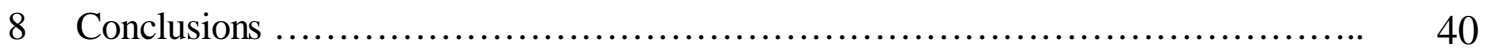

9 Recommendations.................................................... 42

References............................................................. 43 


\section{List of Figures}

Figure 1

Figure 2

Figure 3

Figure 4

Figure 5

Figure 6

Figure 7

Figure 8

Figure 9

Figure 10

Figure 11

Figure 12

Figure 13

Figure 14

Figure 15

Figure 16

Figure 17

Figure 18

Figure 19

Figure 20

Figure 21

Figure 22

Figure 23
Intensive Quenching Phenomenon

Martensite Formation During Quenching...

Layout of Production IQ System Installed at Summit Heat Treating Co...

High-Velocity Single-Part Quenching IQ System and Shaker Hearth

Furnace With IQ 190-gallon Water Tank

New Batch IQ System With 1,900-gallon Water Tank....

Output Shaft....

Input Shaft.

Universal Joint Cross.

Kingpin....

Tripot.

Punch.

Aluminum Extrusion Die

Wear Plate

Base Key.

Lawnmower Tractor Shaft.

Microstructure of $\varnothing 19 \mathrm{~mm}$ Test Bars Made Of 1045 Steel.

Hardness Distribution Of Carburized 1018, 4320, 5120 And 8620 Steels.

Residual Surface Stress Distribution Of Carburized 1018 And 8620

Steels

Residual Stress Distribution For 52100 Steels...

Hardness Distribution Of 52100 Steel.

Production Load With Lawnmower Tractor Shaft....

Layout of Production IQ System Installed at Euclid Heat Treating Co.....

Picture of Production IQ System Installed at Euclid Heat Treating Co.....

\section{List of Tables}

Table 1 Improvement of Part Mechanical Properties and Performance Characteristics Resulting from the IQ Processes.

Table 2

Table 3

Table 4

Table 5

Table 6

Table 7

Table 8

Table 9

Table 10

Project Team members Activities Throughout the Project. .

List of Tested Parts.

Test Bar Calculated Core Cooling Rates......

Thermal Cycles Used For Test Bars.

Mechanical Properties For Small Test Samples. ...

Mechanical Properties For Large Test Samples.

Impact Properties For Small Test Samples.

Impact Properties For Large Test Samples.

Assumption Made for Evaluation of IQ Process Effectiveness Per One

Furnace.

Table 11 Annual Savings Per Integral Quench Furnace of 36"x36"x72".

Table 12

Annuate

Table 13

\section{Rate.....}

Industry.

Table 14

Table 15

Table 16
Annual savings for Heat Treating Industry.....

Annual Savings For One Automotive Coil Spring Production Line....

Summary of Economic, Energy and Environmental IQ Process Benefits for USA Heat Treating Industry.
Page

Page

6 


\section{Executive Summary}

Intensive quenching (IQ) process is an alternative way of hardening (quenching) steel parts through the use of highly agitated water and then still air. It was developed by IQ Technologies, Inc. (IQT) of Akron, Ohio (an EMTEC member-company). While conventional quenching is usually performed in environmentally unfriendly oil or water/polymer solutions, the IQ process uses highly agitated environmentally friendly water or low concentration water/mineral salt solutions. The IQ method is characterized by extremely high cooling rates of steel parts. In contrast to conventional quenching, where parts cool down to the quenchant temperature and usually have tensile or neutral residual surface stresses at the end of quenching. The IQ process is interrupted when the part core is still hot and when there are maximum compressive stresses deep into the parts, thereby providing hard, ductile, better wear resistant parts.

The project goal was to advance the patented IQ process from feasibility to commercialization in the heat-treating and forging industries to reduce significantly energy consumption and environmental impact, to increase productivity and to enhance economic competitiveness of these industries as well as Steel, Metal Casting and Mining industries. The project team included the following companies: IQ Technologies, Inc. (IQT), Akron Steel Treating Co. (AST), Summit Heat Treating Co. (SHT), of Akron, Ohio; Euclid Heat Treating Co. (EHT) of Cleveland, Ohio; General Aluminum Manufacturing Co. (GAM) of Conneaut, Ohio; Case Western Reserve University (CWRU) of Cleveland, Ohio; and the Edison Materials Technology Center (EMTEC) of Dayton, Ohio.

To introduce successfully the IQ technology in the U.S. metal working industry, the project team has completed the following work over the course of this project:

$\Rightarrow$ AST improved capabilities of the existing IQ equipment installed at its facilities.

$\Rightarrow$ IQT performed a number of IQ demonstrations for a variety of steel products made of different tool steels as well as of alloy and plain carbon steels. A total of 33 manufacturers of steel products provided steel parts for IQ trails. IQT conducted IQ demonstrations for 34 different steel parts.

$\Rightarrow$ Our customers tested intensively quenched parts in actual field conditions to evaluate the product service life and performance improvement. The data obtained from the field showed the following:

- Service life (number of holes punched) of cold-work punches (provided by a EHT customer and made of S5 shock-resisting steel) was improved by two to eight times.

- Aluminum extrusion dies provided by GAM and made of hot work H-13 steel outperformed the standard dies by at least $50 \%$.

- Dies provided by an AST customer, made of plain carbon 1045 steel and used for pellet manufacturing outperformed the standard dies by more than $100 \%$.

- Concrete crusher liner wear plates provided by an EHT customer and made of 1045 steel, had the same surface hardness as the plates made of more expensive, pre-hardened high alloy HARDOX®-500 material supplied by a Swedish company and used currently by the EHT customer. The 1045 material intensively quenched wear plates are currently in the field.

- Concrete block molding machine wear plates provided by an IQT customer and made of 8620 steel were processed at the AST production IQ system using a $40 \%$ reduced carburization cycle. An effective case depth in the intensively quenched wear plates was the same as in the standard, oil quenched parts.

- Base keys provided by an EHT customer and made of 8620 steel were processed using a $40 \%$ reduced carburization cycle. The intensively quenched parts showed the same performance as standard parts.

- Other intensively quenched tool products installed in the field are still being evaluated. 
$\Rightarrow$ IQT introduced the IQ process in heat treat practices of three commercial heattreating shops: Akron Steel Treating Co., Summit Heat Treating Co. and Euclid Heat Treating Co.

$\Rightarrow$ CWRU conducted a material characterization study for a variety of steels to develop a database to support changing/modification of recognized standards for quenching steel parts.

$\Rightarrow$ IQT conducted a series of IQ workshops, published seven technic al papers and participated in ASM Heat Treating Society conference and exposition and in Furnace North America Show.

$\Rightarrow$ IQT designed and built a fully automated new IQ system installed at the Center for Intensive Quenching. This system includes the following major components: a stand-alone 1,900-gallon IQ water system, a $\varnothing 24$ "x24" atmosphere pit furnace, and an automated load transfer mechanism.

$\Rightarrow$ IQT established a "Center for Intensive Quenching" at the AST facilities. The 4,000 square feet Center includes the following equipment:

- High-velocity single part quenching IQ unit developed and built previously under EMTEC CT-65 project. The unit is equipped with a neutral salt bath furnace and a high-temperature, electric-fired, atmosphere, box furnace.

○ New 1,900 gallon IQ system with a $\varnothing 24$ "x24" atmosphere pit furnace and a load transfer mechanism.

- Shaker hearth furnace equipped with an IQ water tank and with a chiller to maintain the required water temperature.

The project proven benefits include the following:

$\Rightarrow$ Full elimination or significant reduction of carburizing cycles for a number of steel parts processed at Akron Steel Treating and Euclid Heat Treating companies resulting in a significant increase of the furnace production rate, reduced furnace air pollution emissions and heat treatment process cost.

$\Rightarrow$ Substitution of hazardous oil with environmentally friendly water that preserves the environment, reduces process cost and improves working conditions

$\Rightarrow$ Reduced part distortion

$\Rightarrow$ Improved part service life

Table below summarizes potential savings for the USA Heat Treating industry that could be realized when the IQ process is widely commercialized.

\section{Potential Savings for USA Heat Treating Industry}

\begin{tabular}{|l|l|}
\hline IQ Process Benefit & Annual Benefit for USA Heat Treating Industry \\
\hline $\begin{array}{l}\text { Full elimination or 30\% reduction of } \\
\text { the carburization cycle }\end{array}$ & $\begin{array}{l}\text { Savings of } 1,800 \text { billion Btu of energy } \\
\text { Cost reduction by } \$ 600,000,000 \\
\text { Reduction of CO2 emissions by } 148,000 \text { ton }\end{array}$ \\
\hline Part weight reduction by 5\% & $\begin{array}{l}\text { Savings in material cost of } \$ 70,000,000 \\
\text { Savings of 300 billion Btu of energy }\end{array}$ \\
\hline
\end{tabular}

IQ Technologies Inc. is currently continuing working on commercialization of the IQ process throughout the USA Heat-Treating industry. 


\section{Introduction}

In June 2002, in response to the Department of Energy (DOE) Supporting Industries Solicitation No. DE-PS07-02ID14304 Per U.S., the Edison Materials Technology Center (EMTEC) of Dayton, Ohio submitted a proposal entitled "Intensive Quenching Technology for Heat-Treating and Forging Industries". EMTEC proposed to advance from feasibility to commercialization a patented Intensive Quenching (IQ) technology for steel products in the U.S. Heat-Treating and Forging industries. A complete development and commercialization of the IQ technology in these two supporting industries will significantly reduce energy consumption and environmental impact, thus enhancing the economic competitiveness of the domestic Steel, Metal Casting, and Mining Industries of the Future. DOE granted the proposal, and the project started in April 2003.

The IQ process is an alternative way of quenching steel parts. It was developed by IQ Technologies, Inc. (IQT) of Akron, Ohio (an EMTEC member-company). While conventional quenching is usually performed in environmentally unfriendly oil or water/polymer solutions, the IQ process uses environmentally friendly water or low concentration water/mineral salt solutions. The IQ method is characterized by extremely high cooling rates of steel parts. In contrast to conventional quenching, when parts cool down to the quenchant temperature and usually have tensile or neutral residual surface stresses at the end of quenching, the IQ process is interrupted when the part core is still hot and when there are compressive stresses in the part surface layer. Over the last several years, IQT has conducted hundreds of IQ feasibility trials with a variety of steel products and has proven that the IQ process produces a number of benefits, many of which directly relate to the objectives of the DOE solicitation. These benefits include:

$\Rightarrow$ IQ technology provides high residual compressive stresses in the part surface layer. In current heat-treating practice, when residual surface compressive stresses are required, a very long, highly energy consuming and environmentally unfriendly carburizing process is used or shot peening operations are applied. The IQ method, in many cases, can fully eliminate or significantly shorten the carburizing cycle, or it can fully eliminate shot peening.

$\Rightarrow$ IQ process provides much less part distortion compared to conventional quenching, since the compressed part surface layer works like a "die" maintaining the initial shape of the part and minimizing part distortion. Minimizing straightening operations results in reduced heat-treatment energy usage and costs.

$\Rightarrow$ IQ process can significantly reduce duration or fully eliminate an energy consuming environmentally unfriendly carburization cycle.

$\Rightarrow$ IQ method can be effectively applied immediately after the forging operation is completed using the part residual heat and eliminating the necessity of reheating the part for following quenching. In addition to energy savings, this application of the IQ process provides better part mechanical properties resulting in improved part performance characteristics.

$\Rightarrow$ IQ technique uses plain water instead of hazardous, environmentally unfriendly oil or water/polymer solutions. This significantly reduces the heat-treatment cost and the environmental impact.

$\Rightarrow$ Application of the IQ method to forging and metal casting tooling (dies, die components, etc.) significantly improves both tooling wear and fatigue resistance resulting in longer tooling life, increased press and casting machine productivity, and in the reduction of forging and metal casting operating costs.

$\Rightarrow$ Significant cost reduction of heat-treatment, forging and metal casting operations due to the use of the IQ technology results in improved competitiveness of the U.S. heattreating, forging, and metal casting companies in the world marketplace.

$\Rightarrow$ Part metallurgy and performance characteristics are improved.

The project team included the following companies: IQ Technologies, Inc. (IQT), Akron Steel Treating Co. (AST), Summit Heat Treating Co. (SHT), of Akron, Ohio; Euclid Heat Treating Co. 
(EHT) of Cleveland, Ohio; General Aluminum Manufacturing Co. (GAM) of Conneaut, Ohio; Case Western Reserve University (CWRU) of Cleveland, Ohio; and the Edison Materials Technology Center (EMTEC) of Dayton, Ohio.

To introduce successfully the IQ technology in the U.S. metal working industry, the project team completed the following work over the course of this project:

$\Rightarrow$ Improved capabilities of our existing IQ equipment installed at Akron Steel Treating Co.

$\Rightarrow$ Conducted material characterization study for a variety of steels to develop a database to support changing/modification of recognized standards for quenching steel parts.

$\Rightarrow$ Performed a number of IQ demonstrations for a variety of steel products (a total of 33 manufacturers of steel products provided steel parts for IQ trails).

$\Rightarrow$ Introduced the IQ process into practice of three commercial heat-treating shops: Akron Steel Treating Co., Summit Heat Treating Co. and Euclid Heat Treating Co.

$\Rightarrow$ Conducted a series of IQ workshops, published five technical papers and participated in ASM Heat Treating Society Conference and Exposition and in Furnace North America Show.

IQ Technologies Inc. is currently introducing the IQ process in heat treatment practices of several major automotive parts suppliers, as well as manufacturers of helicopter gear components and aerospace components. 


\section{Background}

Quenching has been known for centuries as part of the heat-treatment process and can be defined as a rapid cooling of the part (usually in oil) from a given temperature (usually above $1,500^{\circ} \mathrm{F}$ ) down to a specified temperature. Quenching is usually a final operation in heat-treat hardening of steel and is used to impart required mechanical properties into the metal parts. Quenching is usually applied to steel products that require high strength, toughness, high resistance to shock, and improved wear characteristics.

An important principle in heat-treating is that the faster the cooling rate during quenching the higher the part's mechanical properties and performance characteristics. On the other hand, the faster the cooling rate the greater the probability of part distortion and cracking. For example, quenching in water provides better part hardness compared to a slower quench in oil, but the probability of part cracking or distortion when quenching in water is higher. Heat-treaters and steel part designers are always balancing between desired hardness and acceptable distortion in choosing the heat-treatment conditions during their processing.

\subsection{Basics of Intensive Quenching}

Several years ago Dr. Nikolia Kobasko discovered a phenomenon that now is positioned to transform the quenching process (References 1-5). The essence of IQ is to quench the steel part uniformly and with a very high cooling rate (several times greater than that in the current, conventional quench process). With this IQ process, beneficial high residual compressive stresses develop on the part surface layer resulting in the drastic reduction of part distortion while concurrently reducing the probability of part cracking. This is in contrast to conventional quenching where there are usually tensile or neutral surface stresses at the end of quench.

In current heat-treating practice, when residual compressive stresses are required on the prt surface, a very long, high energy consuming, and environmentally unfriendly carburizing process is used or expensive and energy consuming shot peening operations are applied. The IQ method, in many cases, can fully eliminate or significantly shorten the carburizing cycle, or it can fully eliminate shot peening operations. Both these benefits result in tremendous energy savings, in an increase of heat-treating equipment productivity, and in reduction of heat-treating furnace emissions.

An additional enhancement is that the IQ process provides superior performance characteristics in the hardened part. A significant added benefit is that the IQ process is environmentally friendly, as intensive quenching is conducted in plain water compared to conventional quenching that usually uses environmentally unfriendly hazardous oil.

Figure 1 illustrates this new IQ paradigm. As seen from Figure 1a, a bell-shaped curve characterizes the probability of cracking (or part distortion) as it relates to the quench cooling rate. The left side of the bell-shaped curve presents the conventional quenching zone, while the right side of the curve presents the previously unknown paradigm of the intensive quenching zone. Figure $1 \mathrm{~b}$ shows that a part's mechanical properties obtained by conventional quenching can be further improved (super-strengthened) by quenching it in the IQ zone. The discovered IQ phenomenon contradicts the common heat-treating practice and is so revolutionary in concept that multiple development demonstrations have been required to generate enough data to confirm to metallurgists that this alternative method of quenching steel products can dramatically transform conventional heat-treating approaches. 


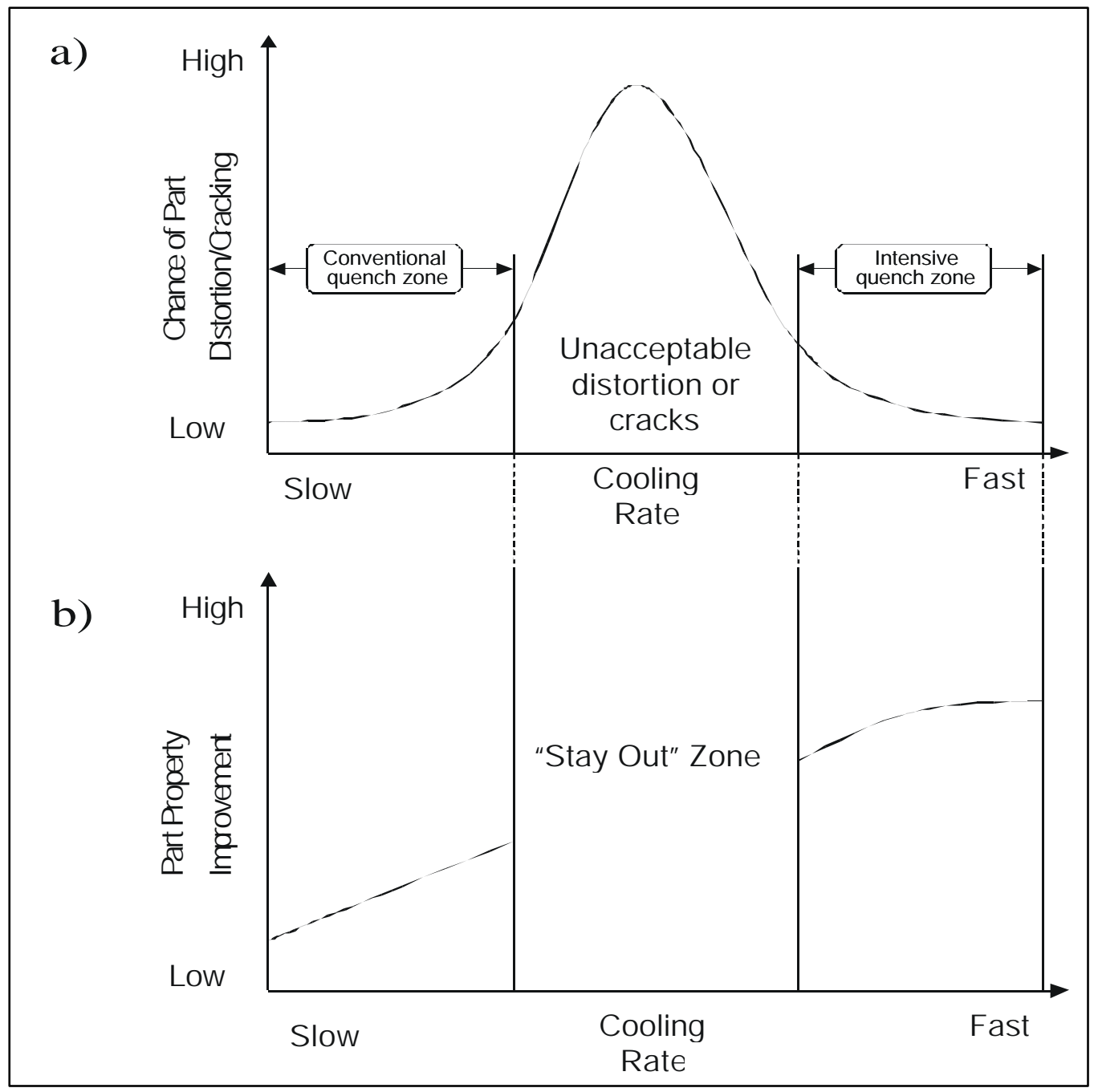

Figure 1. Intensive Quenching Phenomenon (Bell-shaped curve)

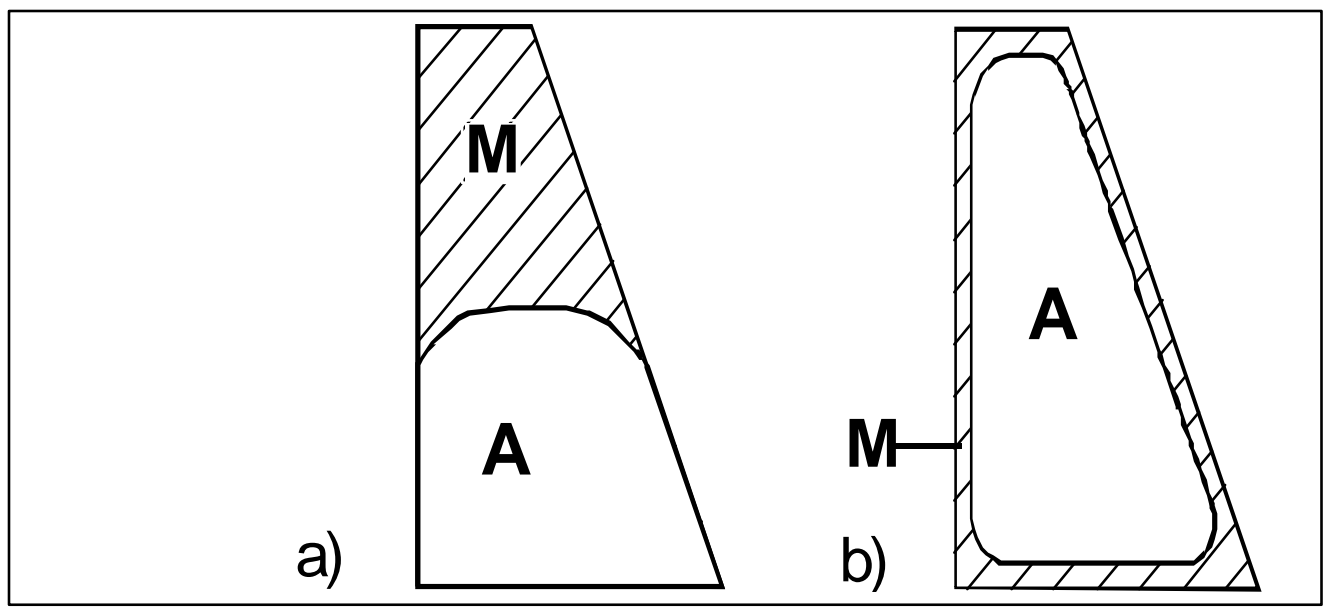

Figure 2. Martensite Formation During Quenching in Tapered Ring 
Figure 2 illustrates graphically how the IQ process works for a tapered ring. During quenching, the steel changes its structure from an initial unhardened structure (austenite) to a stronger final structure (usually martensite). The martensitic structure starts forming on the part surface after the surface reaches a certain temperature and propagates into the part core as the core cools. It is important to note that final steel structures after quenching have a greater specific volume than the initial austenitic structure.

In other words, steel expands as a result of quenching. This expansion in the part's volume (from austenite phase to martensite phase) is about four percent, and it is the cause of much of the distortion and cracking from traditional quenching. As shown in Figure 2a, in conventional quenching, the martensitic structure forms first in the thin sections of the parts since the thin section cools faster compared to the thick part section. Non-uniform formation of the martensitic structure throughout the part and volume growth from martensite cause the part to distort and to form residual tensile stresses on the part surface.

In intensive quenching, the part is cooled very uniformly and so rapidly that the structural changes in the steel occur simultaneously over the entire part surface (Figure 2b) forming a martensite "shell." The shell forms because the heat extraction by the quenchant is so great that it prevails over the heat supply from the part core, even in the thick sections of the part. Thus, in contrast to conventional quenching, a strong martensitic layer encapsulates the whole part being intensively quenched from the very beginning of quenching. Each element of the surface layer expands while transforming into the martensitic structure. Expanded surface layer elements are restrained against each other and against the part core creating beneficial residual surface compressive stresses. The part surface layer is building up its strength and compression while the martensitic structure continuously propagates towards the part core as it cools by conduction through the shell. At some point in time, the residual compressive stresses reach their maximum value. At that time, intensive quenching is interrupted. The firm martensitic case with surface compressive stresses works like a "die" maintaining the initial shape of the part and minimizing part distortion and the probability of cracking. This phenomenon is the central concept in understanding how this new process is an enabling technology in designing dramatically improved parts or reducing manufacturing costs in the U.S.'s core metal and manufacturing industries.

The key elements of the IQ method are the following: a) determining a rate of part cooling that forms the martensitic shell uniformly throughout the entire part surface area, and b) establishing an optimum cooling time that provides maximum residual compressive surface stresses. Answers to how one can know what cooling rate to apply and when the rapid cooling should be interrupted depend upon part geometry and the metal alloy selected. The above developmental work combined with a proprietary computer program developed and validated by Dr. Kobasko and his colleagues for modeling thermal, stress, and structural conditions in parts of different shapes addresses these issues. This technology, with the help of the DOE funds, can now be developed into a scaled-up demonstration of this IQ process technology and further developed in conjunction with the potential commercialization opportunities.

For the first time in heat-treating of steel, IQ allows the heat-treater to have both high hardness and low distortion from the same quench process. Table 1 summarizes experimental data obtained by IQT on the improvement of part mechanical properties and performance due to the use of the IQ processes compared to conventional quenching (References 615). This table includes feasibility data obtained by IQT's customers for many parts such as bearing products, tooling steel, and automotive parts (torsion bars, stabilizers, coil springs, etc.). Non-proprietary data is available upon request. 
Table 1

Improvement of Part Mechanical Properties and Performance Characteristics

Resulting from the IQ Processes

\begin{tabular}{|l|l|l|}
\hline \multicolumn{1}{|c|}{ Steel Part } & $\begin{array}{l}\text { Property/Performance } \\
\text { Characteristic }\end{array}$ & \multicolumn{1}{c|}{ Improvement } \\
\hline $\begin{array}{l}\text { Springs, shafts, bearing rollers, } \\
\text { bearing rings, fasteners, mining } \\
\text { machine sprockets }\end{array}$ & Surface hardness & Up to 10\% \\
\cline { 2 - 3 } & Core hardness & Up to 50\% \\
\cline { 2 - 3 } Forklift forks, fasteners, springs & Hardened depth & Up to 6 times \\
\hline Punches, dies, fasteners & Strength & 20-30\% \\
\hline $\begin{array}{l}\text { Punches, dies, springs, automotive } \\
\text { shafts }\end{array}$ & $\begin{array}{l}\text { Service life/fatigue } \\
\text { resistance }\end{array}$ & Up to 3 times \\
\hline
\end{tabular}

In addition to the above demonstration experiments, IQT and a major U.S. manufacturer of railroad parts conducted a demonstration study to validate an ability of the IQ process to eliminate fully, or to shorten significantly, the carburization cycle for steel parts (Reference 16). The study was conducted for forged shoes and wedges that are components of draft gears made by this manufacturer. The shoes and wedges were made from the standard material, but the shoes were not carburized at all while the wedges were carburized to a half of their standard case depth. The results of the load and fatigue tests performed by the customer showed that the performance characteristics of the intensively quenched non-carburized shoes and partially carburized wedges were the same or better than the performance characteristics of the carburized shoes and wedges that were conventionally quenched. We conducted a similar study for universal joint crosses (Reference 17). The results of this study proved that an overall duration of the carburization cycle for the UJ crosses could be reduced by more than $30 \%$.

IQT's experiences show that the process can be effectively applied to steel parts right after forging operations are completed using the part residual heat. The studies showed that, in this application, the IQ method not only saves energy, but also improves part mechanical properties.

The IQ technology provides the following benefits:

$\Rightarrow$ Reduced energy consumption in heat-treating and forging operations due to a significant reduction or full elimination of the energy consuming carburization cycle.

$\Rightarrow$ Higher production rates of heating and quenching equipment, shorter cycle times, and reduced lead times.

$\Rightarrow$ Reduced part distortion and less post-heat-treat processing.

$\Rightarrow$ Cleaner and safer working environment; reduced hazardous waste generation in heattreating operations (no oil).

$\Rightarrow$ Improved market competitiveness for USA's equipment manufacturers, part suppliers, and heat-treaters.

$\Rightarrow$ Products with improved quality and performance characteristics (better metal hardness, strength, wear resistance, and service life, lighter but yet stronger product, etc.).

\subsection{Domestic and Worldwide Technology Status}

At the present time, both domestic and overseas heat-treating companies do not use the IQ technology as defined above: very rapid and uniform quenching that is interrupted when residual surface compressive stresses are at their maximum value. Some U. S. companies, for example Caterpillar and Ford Motor Company, apply intensive (or as they call it "drastic") quenching processes in water or in brine to their products. However, these processes do not yield maximum residual surface compressive stresses since they are not interrupted at the optimum time. These "drastic" quenches were developed based on limited practical data rather than computer 
simulations. The IQ process is actually the only new technology for hardening steel parts that is currently emerging in the U.S. heattreating market.

While there is currently no known direct competition to the IQ process, there is non-direct competition to some of the intensive quenching benefits. For example, a new method of creating surface compressive stresses, laser shot peening, is emerging. This method, in contrast to conventional shot peening, does not impair conditions of the part surface. However, unlike IQ technology, laser shot peening is still a very expensive method and it cannot be applied to parts of complex geometry. Another example of competing technology is micro alloys that allow quenching of steel parts in air providing the proper hardness and minimum part distortion. The disadvantage of this method is that micro alloys are quite expensive and cooling the parts in air slows the heat-treating process.

\section{Why DOE Support Was Needed}

Over the years, the technical leaders of IQT have performed hundreds of experiments proving this new quenching technology. In 1999, IQT launched an IQ demonstration project funded by EMTEC. Over the course of this project, two experimental quenching systems were designed and constructed: a 500-gallon system using a low-pressure propeller, and an 800-gallon unit using a high-pressure, 600-gpm pump. A salt bath furnace was used for heating steel parts prior to quenching them in the two experimental IQ units. In addition to the two experimental units, Akron Steel Treating Company modified its 6,000-gallon production quench tank to utilize the IQ process. This tank is coupled to an atmospheric furnace for heating steel parts prior to quenching. A large number of successful feasibility tests have been conducted and verified in these IQ units, demonstrating the benefits of IQ on a variety of steel parts. Even with successful feasibility demonstrations of the IQ technology on steel parts, several significant barriers have hindered commercialization:

$\Rightarrow$ Limited IQ process demonstration capabilities

○ We could not conduct IQ trials for tool steels that require a heating temperature above $1,600^{\circ} \mathrm{F}$.

- We could not accurately implement calculated cooling recipes in our production 6,000-gallon IQ system because its lifting mechanism is too slow and the unit is not equipped with proper controls.

$\Rightarrow$ Lack of commercial IQ installations (only one heat treating company, Euclid Heat Treating Co., had a production IQ system).

$\Rightarrow$ Absence of industry standards for the IQ process.

$\Rightarrow$ Lack of a steel properties database for computer simulation.

$\Rightarrow$ Limited capabilities in commercialization of the IQ technology.

DOE support was critical to expand the capabilities of IQT's existing IQ systems to be able to process a wider variety of tool products and to provide optimum or close to optimum IQ conditions during demonstration. The DOE funding was needed to facilitate new installations of IQ equipment in the U.S. plants needed to accelerate the commercialization process. The DOE funding was also required to facilitate a process of generating a database for mechanical and thermal properties for a variety of steels needed for computer calculations of IQ cooling recipes and development of new standards. The DOE support was needed to enhance our demonstration activities including initial contact and follow-up to interested companies. In addition, support was required for conducting IQ Workshops at a variety of sites. Other commercialization activities include technical papers, trade shows, and exhibits of the technology, etc. 


\section{Project Goal, Statement of Work and Team}

\subsection{Project Goal}

The major goal of this project was to narrow the "gap" between feasibility testing and commercialization of the IQ technology by pocessing parts in pre-production IQ systems to demonstrate reproducibility and uniformity of part quenching to companies throughout the U.S. industrial sector. The project team focused on the demonstration/validation of the following two IQ process benefits: full elimination or significant shortening of the carburization cycle and improvement of the service life of tooling, including aluminum extrusion dies and die components. Additional goals of the project were a) to improve existing production IQ equipment installed at Akron Steel Treating Co. to extend IQ process demonstration capabilities, b) to develop steel properties databases to support changing/modifying recognized standards for quenching steel parts, and c) to introduce the IQ method in heat treat practices.

\subsection{Project Statement of Objective}

The project objectives fall into five categories:

$\Rightarrow$ Expand demonstration capabilities of the existing IQT systems (both the experimental and production) installed at the Akron Steel Treating Co. facilities.

$\Rightarrow$ Accelerate the demonstration/validation of the benefits of the IQ technology to heattreaters, parts manufacturers, and product design engineers.

$\Rightarrow$ Introduce the IQ process in the heat-treating practices of the project participants.

$\Rightarrow$ Develop an extensive body of data for intensively quenched parts to support changing/modifying recognized standards for quenching steel parts.

$\Rightarrow$ Commercialize aggressively the IQ technology in different steel part manufacturing industries.

\subsection{Project Team}

A list of the project participants and their roles are presented in Table 2. The project team has extensive experience in heat-treatment, in the use and testing of forged and heat-treated steel parts, and in project management. Akron Steel Treating, Summit Heat Treating, and Euclid Heat Treating companies are commercial heat-treaters with over 2,000 customers and have been in the business for over 50 years. These three companies cover the complete spectrum of heat-treating operations, including carburization of steel parts.

General Aluminum Manufacturing Co. is a leading supplier of permanent mold aluminum castings to the automotive industry. Case Western Reserve University is a leading university in materials science. Its Materials Science Department has state-of-the-art facilities for conducting a wide variety of metallurgical analyses. IQ Technologies, Inc. is an engineering consulting company that owns the patented IQ technology and the software package that is used for calculating IQ cooling recipes. The company has extensive experience in designing IQ systems for various applications. Edison Material Technology Center is a not-for-profit organization that has extensive experience as an objective third-party team builder with project management expertise whose role is to overcome roadblocks to swift commercialization of technology, i.e. acceleration of technology to the marketplace. Project teams on EMTEC's projects include government labs, industry, small businesses, universities, and other not-for-profits. 
Table 2. Project Team Members Activities Throughout the Project

\begin{tabular}{|c|c|}
\hline Project Participant & Activities \\
\hline $\begin{array}{l}\text { Heat-treating } \\
\text { companies: } \\
\text { - Akron Steel Treating } \\
\text { - Summit Heat } \\
\text { Treating } \\
\text { - Euclid Heat Treating }\end{array}$ & 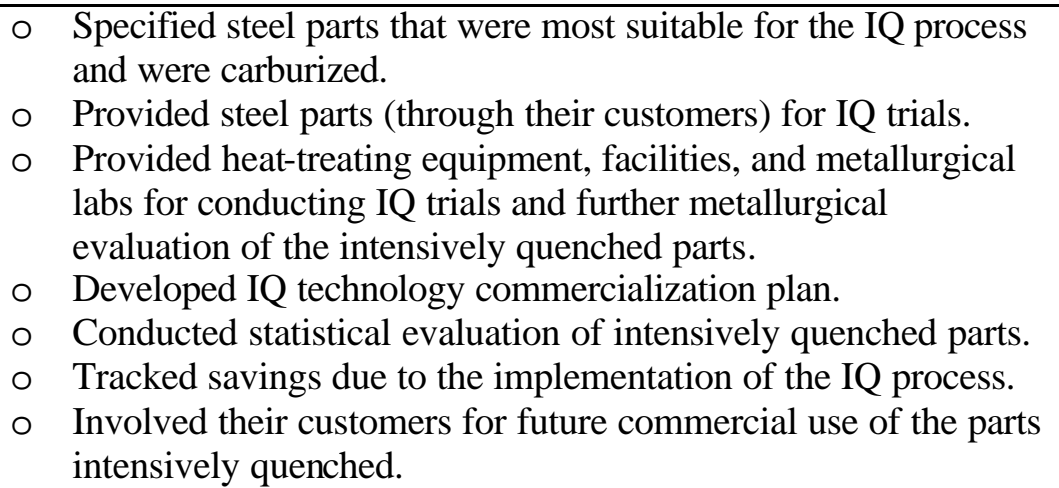 \\
\hline $\begin{array}{l}\text { End-User: } \\
\text { General Aluminum } \\
\text { Manufacturing }\end{array}$ & $\begin{array}{l}\text { Specified and made extrusion dies and die components for IQ } \\
\text { trials. } \\
\circ \text { Conducted field evaluation of intensively quenched dies and die } \\
\text { components. } \\
\circ \text { Track savings due to the implementation of the IQ process }\end{array}$ \\
\hline $\begin{array}{l}\text { Case Western Reserve } \\
\text { University }\end{array}$ & $\begin{array}{l}\text { Conducted material characterization study and detailed } \\
\text { metallurgical analysis of intensively quenched parts. }\end{array}$ \\
\hline IQ Technologies, Inc. & $\begin{array}{ll} & \text { Developed IQ recipes for specified steel parts using its } \\
\text { proprietary software packages. } \\
\circ \text { Conducted IQ trials. } \\
\circ \text { Designed and built pre-production IQ units for project } \\
\text { participants, provide engineering support in IQ systems } \\
\text { installation and troubleshooting during IQ technology } \\
\text { introduction. }\end{array}$ \\
\hline $\begin{array}{l}\text { Edison Materials } \\
\text { Technology Center }\end{array}$ & $\begin{array}{l}\text { Managed the project activitie s and provided support in IQ } \\
\text { technology transfer and commercialization. }\end{array}$ \\
\hline
\end{tabular}




\section{Improvement of Existing Intensive Quenching Process Capabilities}

\subsection{Modification of Production IQ Water Tank}

Figure 3 presents a layout of the first production IQ system that was installed at Summit Heat Treating Co. in 1999. The system consists of a Surface Combustion atmosphere furnace having a work-zone of $91 \mathrm{~cm} \times 91 \mathrm{~cm} \times 122 \mathrm{~cm}\left(36 " \times 36 " \times 48\right.$ ") and an IQ water quench tank of $22.7 \mathrm{~m}^{3}$ (6,000 gallons) placed across the aisle from the furnace. A cart is used to move the load from the furnace to the quench tank.

The mild steel IQ tank is equipped with four $46 \mathrm{~cm}$ (18") propellers that are rotated by four motors. The tank uses a water/sodium nitrite solution of low concentration (8-10\%) as the quenchant. A quenchant flow velocity in the tank is about $1.5 \mathrm{~m} / \mathrm{sec}(5 \mathrm{ft} / \mathrm{sec})$ as it passes over the parts. An air-cooling system maintains the quenchant temperature within the required limit. As production increases a chiller will be required to maintain the $25^{\circ} \mathrm{C}$, or less, bath temperature. Over the last several years, we have quenched a number of different experimental loads in the 6,000-gallon production IQ system: forklift forks, wedges and shoes (components of railroad car coupling systems), punches, ball studs, plow blades, leaf springs, etc. The load mass ranged from several kilograms to about 800 kilograms (about 1,800 lb).

The major shortcomings of the IQ tank design were the following:

$\Rightarrow$ Relatively long time required for transferring the load from the furnace to the IQ tank resulting in possible overcooling the parts of small cross sections prior to quenching.

$\Rightarrow$ Slow movement of the IQ tank elevator resulting in significantly different cooling times between the parts placed in the lower and upper layers of the load.

$\Rightarrow$ Manual operation of the elevator.

$\Rightarrow$ Manual control of the cooling time.

During the course of the project, the following work has been done to improve the IQ system at Summit Heat Treating Co.:

$\Rightarrow$ Completed the automation of the 6,000-gallon IQ tank by developing and installing an advanced control system including a PLC and proper automated valves. The PLC is now fitted to the unit to automate the movement of the load.

$\Rightarrow$ Improved lifting mechanism to minimize loading/unloading cycle time by retrofitting of the existing air cylinders. The elevator "down" cycle has been reduced from 12 seconds to 2 seconds, and the up time from 12 seconds to 3 seconds out of the tank.

$\Rightarrow$ Designed and installed a rear load handling system that reduces the load transferring time from the furnace to the IQ tank from 30-40 seconds to 10-15 seconds.

Note that all IQ demonstrations conduced at Summit Heat Treating Co. and described in Section 4 were performed in the modified 6,000-gallon IQ water tank. 


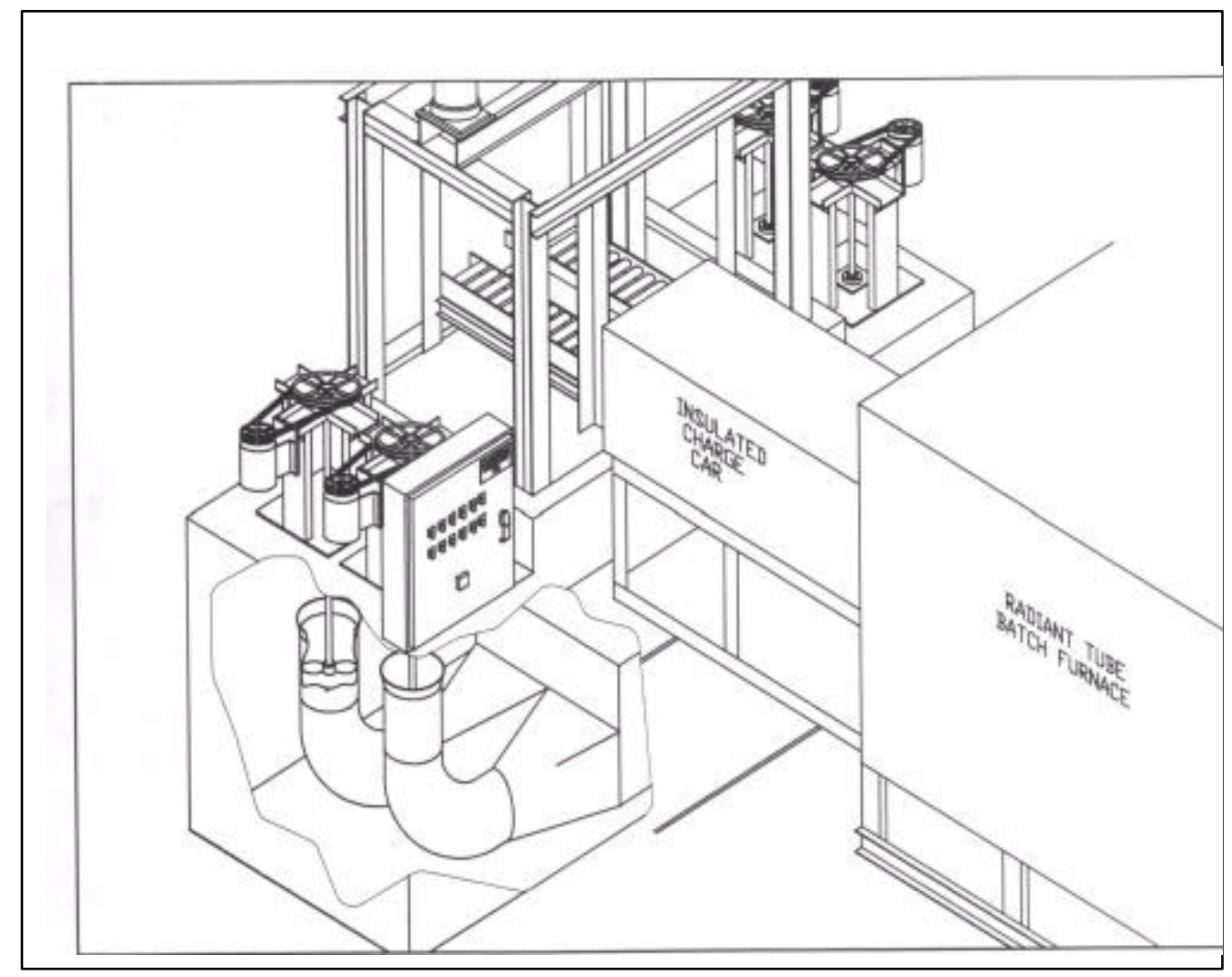

Figure 3. Layout of Production IQ System Installed at Summit Heat Treating Co.

\subsection{Establishing of Center for Intensive Quenching}

The Center for Intensive Quenching is designed to implement the IQ processes for a variety of steel parts. The Center's mission is two fold: a) to demonstrate and to validate the IQ processes on an industrial scale basis, and b) to generate revenues for IQT by processing production loads. The Center for Intensive Quenching includes the following IQ equipment:

$\Rightarrow$ Single-part quenching high-velocity IQ system.

$\Rightarrow$ Batch quenching IQ system.

$\Rightarrow$ Continuous IQ system.

Figures 4 and 5 present pictures of the above IQ equipment installed in the Center for Intensive Quenching. The sections below describe designs of the IQ systems and their operation.

3.2.1 Single -Part Quenching IQ System. The single-part quenching high-velocity IQ system includes the following major components (Figure 4):

$\Rightarrow 800$-gallon water tank equipped with high-pressure 600-gpm pump, loading/unloading lift table, three-way valve, piping, controls, etc. (see details in Reference 3)

$\Rightarrow \varnothing 12$ "x $18 "$ neutral salt bath furnace with a maximum heating temperature of $1,700^{\circ} \mathrm{F}$

$\Rightarrow 8$ "x8"x12" electric box atmosphere furnace capable of heating parts up to $2,300^{\circ} \mathrm{F}$

The part to be quenched is through-heated in either of the above two furnaces depending on the part size and required heating (austenitizing) temperature. The part is manually transferred from the furnace to the IQ tank. A sample sequence of operations of the high-velocity IQ unit is presented in details in Reference 18. 
Note, the above electric box atmosphere furnace allows processing tool products made of high alloy steels that require a high temperature heating cycle (above $2000^{\circ} \mathrm{F}$ ) and that are usually processed in vacuum furnaces. These high alloy steels are usually "air" or "gas pressure" quenched and include the following: molybdenum high-speed steels, tungsten high-speed and hot-work steels, and some chromium hot-work steels.

3.2.2 Batch Quenching IQ System. The batch IQ system (Figure 5) includes the following major components:

$\Rightarrow$ 1,900-gallon water tank described in Section 2.2 above.

$\Rightarrow$ Atmosphere pit type furnace with a working space of $\varnothing 24 " x 24$ "high. The furnace is equipped with electrically heated elements, a fan attached to lid (door), an automated, pneumatically operated lid, a thermocouple for controlling the furnace temperature, and an oxygen probe for controlling the furnace's protective atmosphere. Parts are heated in the furnace in typical fixtures equipped with a center pole. The fixture center pole has a ring at the top of the pole for picking and carrying the load. The fixture with parts is placed on the furnace supports.

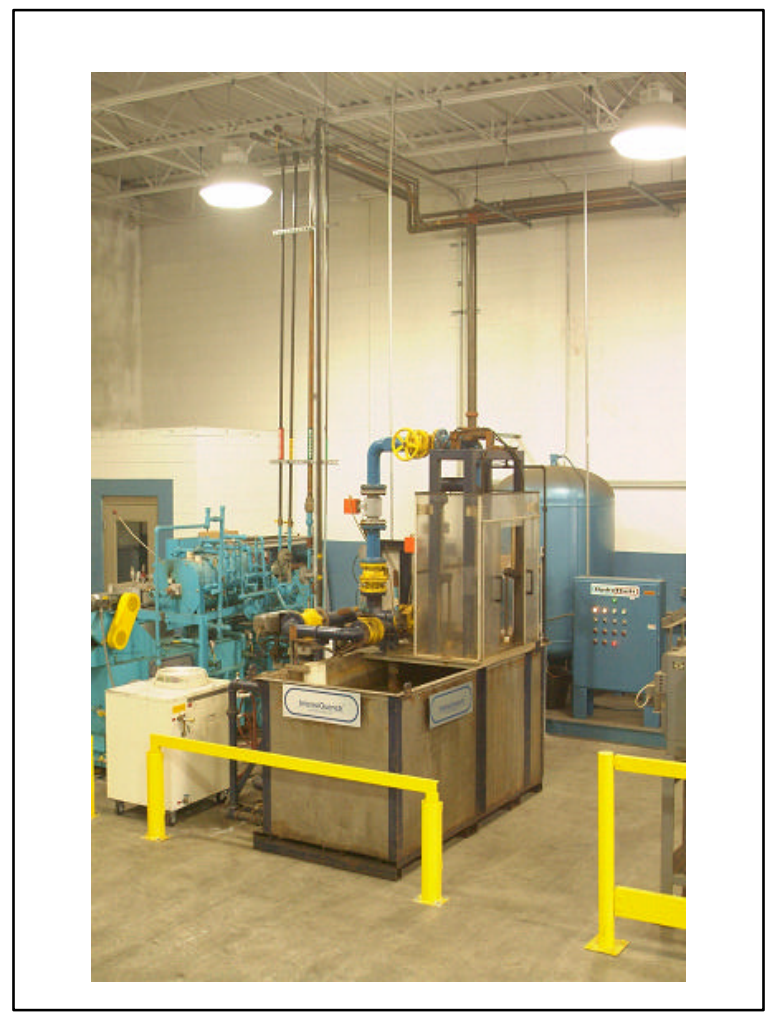

Figure 4. High-Velocity Single-Part Quenching IQ System and Shaker Hearth Furnace with IQ 190-gallon Water Tank 


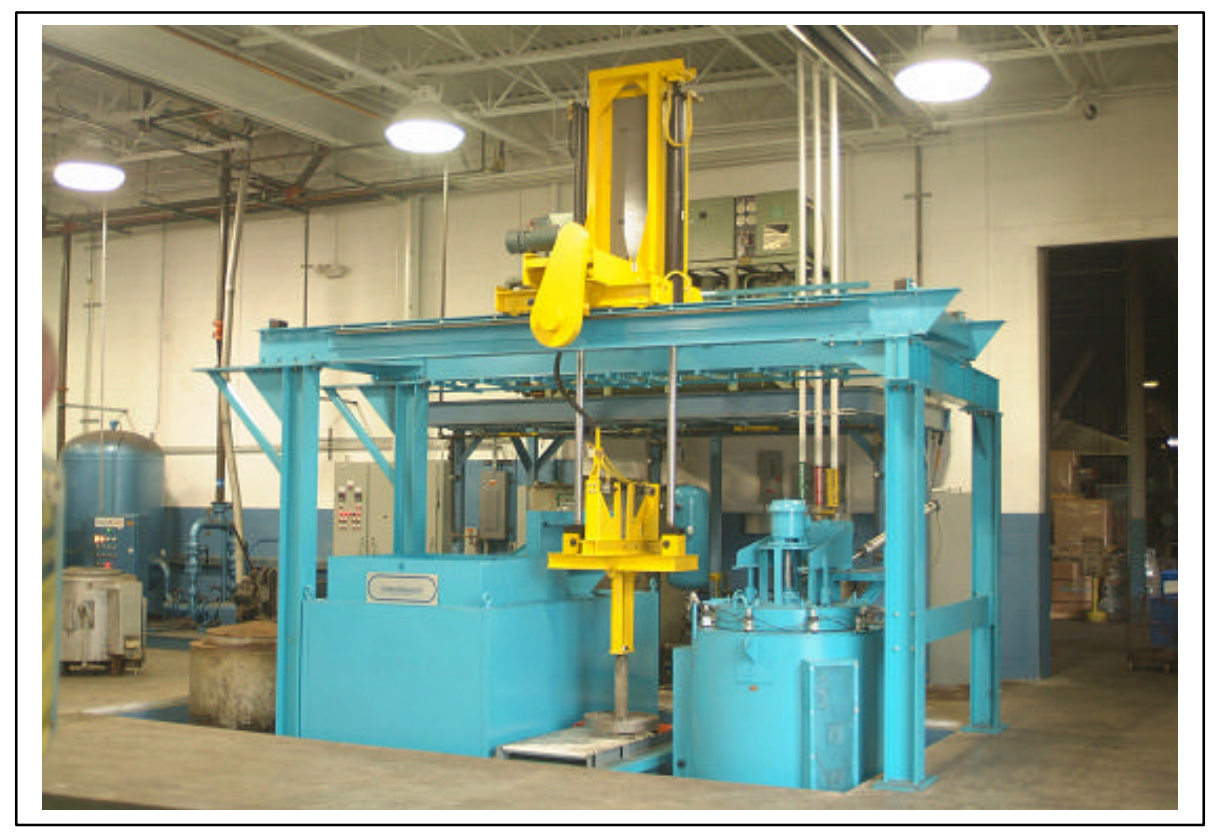

Figure 5. New Batch IQ System With 1,900-gallon Water Tank

$\Rightarrow$ Loading/unloading table that is designed to place the load prior to loading the parts into the furnace and to place already quenched parts before transferring them to a tempering furnace. The loading/unloading table can move along the rails towards the aisle so the load can be placed on or taken from the loading/unloading table by a forklift.

$\Rightarrow$ Load transfer system that is designed to transfer the load from the loading/unloading table into the furnace, or from the furnace into the 1,900-gallon quench tank, and from the quench tank back to the loading/unloading table. The load transfer system includes the following major components:

- Steel frame consisting of four vertical columns and two horizontal I-beams.

- Two load transfer mechanisms: one that transfers the load in horizontal direction and another one that transfers the load in vertical direction.

- Carriage providing a horizontal movement of the load.

- Electrical motor located on the carriage, a rack pinion drive and a linear bearing placed on two horizontal beams providing fast and controllable movement of the carriage.

- Two air cylinders with two linear bearings attached to the carriage that provide a vertical movement of the load.

- Pneumatic lock attached to the air cylinders.

The system's mode of operation is the following. Initially, the fixture with the batch of parts to be heat treated is on the loading/unloading table, the carriage is above the loading/unloading table, the air cylinders are completely retracted, the pneumatic gripper is in a top position and is unlocked, pneumatic gripper aligns with the fixture center pole. The load transfer mechanism operates in four steps:

$\Rightarrow \quad$ Step 1: This step starts after the operator opens the furnace door. The air cylinders move the pneumatic gripper down towards the fixture with parts. The pneumatic gripper grips the ring attached to the fixture center pole and locks in place. The air cylinders move the load up from the loading/unloading table to the upper position.

$\Rightarrow \quad$ Step 2: The carriage moves the load towards the furnace. The carriage stops above the furnace working space so that the fixture center pole aligns with the furnace axis. The air cylinders lower the load into the furnace. After the load is 
placed on the furnace load supports, the pneumatic gripper releases the fixture center pole ring, and the air cylinders move the pneumatic gripper to the upper position (the air cylinders are fully retracted). At the end of Step 2, the operator closes the furnace door. The carriage remains above the furnace till the heating cycle is over.

$\Rightarrow \quad$ Step 3: When the heating cycle is completed, the operator opens the furnace door. The IQ tank prop is ON (the prop should be turned on one minute or so prior to the completion of the heating cycle). The retractable guard on the top of the IQ tank moves to clear the way for the load being transferred from the furnace to the IQ tank quench section. The air cylinders push the pneumatic gripper towards the fixture center pole ring; the pneumatic gripper grips the ring and locks. The air cylinders move the load to the upper position (the air cylinders are fully retracted). The carriage moves the load to over the IQ tank. The carriage stops above the IQ tank quench so that the fixture center pole aligns with the quench section axis. The retractable guard moves back and seals the area around the quench section. The air cylinders lower the load into the quench (the air cylinders are fully extended). The load is kept in the quench for the specified time after which the gripper cylinders pull the load out from the intensive water quench and into the air.

$\Rightarrow \quad$ Step 4: The load transfer mechanism operation in Step 4 depends on what type of the IQ process is applied (IQ-3 or IQ-2):

- Step 4a: If a one-step quenching (IQ-3) process is used, the retractable guard opens and the carriage moves the load back to the loading/unloading table. The retractable guard moves back and seals the area around the quench section. The IQ tank prop is turned off. The air cylinders lower the load onto the loading/unloading table. The pneumatic gripper releases the fixture ring. The air cylinders move the pneumatic gripper up and out of the way. The load is ready to be transferred to a tempering furnace; OR

- Step 4b: If a three-step (IQ-2) process is used, the load is kept in the air for a specified period of time to allow self-tempering of the intensively quenched shell by the hot core of the part. Then the air cylinders push the load back into the quench. The load is kept in the quench for a specified time after which the gripper pulls the load out from the quench. The retractable guard opens and the carriage moves the load back to the loading/unloading table. The retractable guard moves back and seals the area around the quench section. The IQ tank prop is turned off. The air cylinders push the load down and place it on the loading/unloading table. The pneumatic gripper releases the fixture ring. The air cylinders move the pneumatic gripper up and out of the way. The load is ready to be transferred to a tempering furnace.

Operator closes the furnace door after Step 4 is completed.

The IQ unit control system includes the following controls and safety sensors/switches:

$\Rightarrow$ Sensor controlling the furnace door position, so that Step 1 can be initiated only if the furnace door is open.

$\Rightarrow$ Sensor controlling the condition of the pneumatic lock, so that the air cylinders start pulling the load up from the loading/unloading table only if the pneumatic lock is locked.

$\Rightarrow$ Sensor controlling the position of the air cylinders, so that the carriage starts moving only when the air cylinders are fully pulled in (the load is in the upper position).

$\Rightarrow$ Sensor controlling the position of the retractable guard so that the carriage starts moving to and from the IQ tank only when the guard is open.

$\Rightarrow$ Sensor controlling the mode of the prop so that the carriage starts moving to the IQ tank only when the prop is ON.

$\Rightarrow$ Proximity switches controlling the position of the load on the loading table. 
$\Rightarrow$ Proximity switches controlling the position of the carriage, so that the air cylinders starts pushing the pneumatic lock down towards the load only if it is aligned with the fixture center pole ring; and the air cylinders start pushing the load down into the furnace or into the quench only when the fixture center pole is aligned with the furnace axis or with the quench section axis respectively.

$\Rightarrow$ Sensor controlling the carriage acceleration and deceleration.

$\Rightarrow$ Sensor controlling water temperature.

$\Rightarrow$ Sensor measuring the sodium nitrite content in the water.

$\Rightarrow$ Sensor monitoring the prop rpm and amps.

Note that the total transfer time of the load from the furnace to the 1,900-gallon quench tank is less than 12 seconds. This time includes the time to pull the load from the furnace, the time to transfer the hot load from the furnace to the IQ tank quench section, and the time to fully immerse the load into the quench.

3.2.3 Continuous IQ System. The continuous IQ system includes a shaker hearth furnace equipped with an IQ water tank described in Section 2.3 above (see Figure 4 above). The key elements of the unit design are the following:

$\Rightarrow$ The furnace chute that is equipped with a set of water nozzles that provides a very intensive agitation within the chute resulting in high convective heat transfer. A high heat extraction rate from the part within the chute results in a complete elimination of a non-uniform quenching from the sporadic film boiling stage of heat transfer. By the time the part being quenched falls through the intensive quench chute and onto the furnace conveyor, the thermal energy contained in the part surface is not enough to support film boiling.

$\Rightarrow$ The furnace conveyer has a variable speed that allows a dwell time in the water quench that is specified by the computer model. For the parts of a complex shape, it is very important to maintain thermal energy in the part core by the end of cooling in the intensive quench chute to provide self-tempering of the part hardened case and to fully eliminate a possibility of part cracking.

$\Rightarrow$ The 190-gallon IQ tank is equipped with a chiller that maintains the water temperature within a specified range (usually from $65^{\circ} \mathrm{F}$ to $70^{\circ} \mathrm{F}$ ).

The current status of the IQ equipment installed at the Center for Intensive Quenching is as follows:

$\Rightarrow$ Single part quenching high-velocity IQ system is fully operational.

$\Rightarrow$ Electric atmosphere box furnace used for heating parts prior to quenching in the above IQ unit is fully operational.

$\Rightarrow$ Neutral salt bath furnace designed for heating parts prior to quenching in the highvelocity IQ unit to be equipped with a salt pot and controls.

$\Rightarrow$ New batch type IQ system to be wired with proper controls and to be tuned.

$\Rightarrow$ Shaker hearth furnace with an IQ water tank is fully operational. 


\section{Demonstration and Validation of Intensive Quenching Technology}

Over the course of the project, we conducted a number of demonstration IQ trials for a variety of products such as automotive parts, tool products, fasteners, etc. The parts were made of different alloy, plain carbon steels and carburized grades of steel as well as of tool steels that are traditionally quenched in oil, air or inert gas. Table 3 summarizes the IQ demonstrations we have performed. As an example, Figures 6-15 shows the pictures of some of the intensively quenched parts. We processed a total of 34 different steel parts provided by 33 steel product manufacturers. To evaluate the metallurgy of the intensively quenched parts, we measured the following parameters: surface and core hardness, micro hardness and effective case depth for carburized grades of steels.

A majority of steel parts presented in Table 3 have favorably responded to the IQ process. For example:

$\Rightarrow$ Tripots and output shafts significantly improved fatigue resistance compared to standard oil quenched parts.

$\Rightarrow$ Universal joint crosses heat-treated using a 30\% shorter carburization cycle had the same both metallurgical and performance characteristics as the standard crosses carburized and quenched in oil.

$\Rightarrow$ Punches made of shock-resistance S5 steel demonstrated a service life improvement from $100 \%$ to $800 \%$.

$\Rightarrow$ Aluminum extrusion dies made of hot work $\mathrm{H}-13$ steel out performed the standard, air quenched dies by at least $50 \%$.

$\Rightarrow$ Dies made of plain carbon 1045 steel and used for pellet manufacturing out performed the standard, oil quenched dies by more than $100 \%$.

$\Rightarrow$ Concrete crusher liner wear plates made of plain carbon 1045 steel had the same surface hardness as the more expensive, Swedish-sourced, pre-hardened high alloy HARDOX®500 material used currently by the customer.

$\Rightarrow$ Concrete molding machine wear plates made of 8620 steel were processed using a shorter carburization cycle. The intensively quenched parts showed the same effective case depth as parts carburized in a $40 \%$ longer cycle and then quenched in oil.

$\Rightarrow$ Base keys made of 8620 steel were processed using a $40 \%$ shorter carburization cycle. The intensively quenched base keys showed the same performance as the same parts carburized in a $40 \%$ longer cycle and quenched in oil.

$\Rightarrow$ Gear blanks made of 4140 and 4340 steels and used for manufacturing rack and pinion gears for U.S. Navy showed better strength and toughness after intensive quenching compared to standard oil-quenched parts.

Some of the steel products we quenched intensively are still in the field under the customer evaluations (the coil springs, chisels, wear plates, hammers). Some of the tested parts did not respond well to the IQ method due to different reasons (for example, both the extrusion tips provided by an IQT customer and the digging teeth provided by a EHT customer developed cracks on the surface due to complex part geometries that did not allow the parts to be batch, intensively quenched. Also, we could not provide required surface conditions for the sockets provided by an IQT customer and made of 40B25 steel (the surface had an excessive oxidation due to an absence of the right combination of atmosphere heating equipment and IQ equipment at the time of IQ trials). 


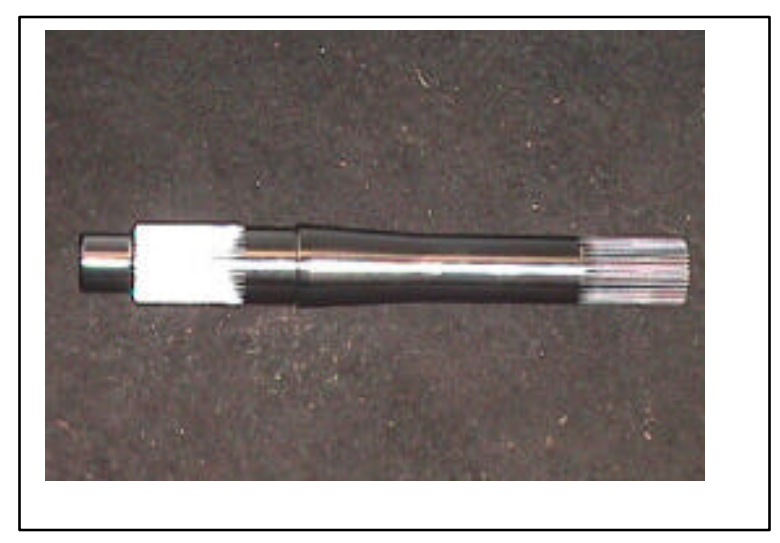

Figure 6. Output Shaft

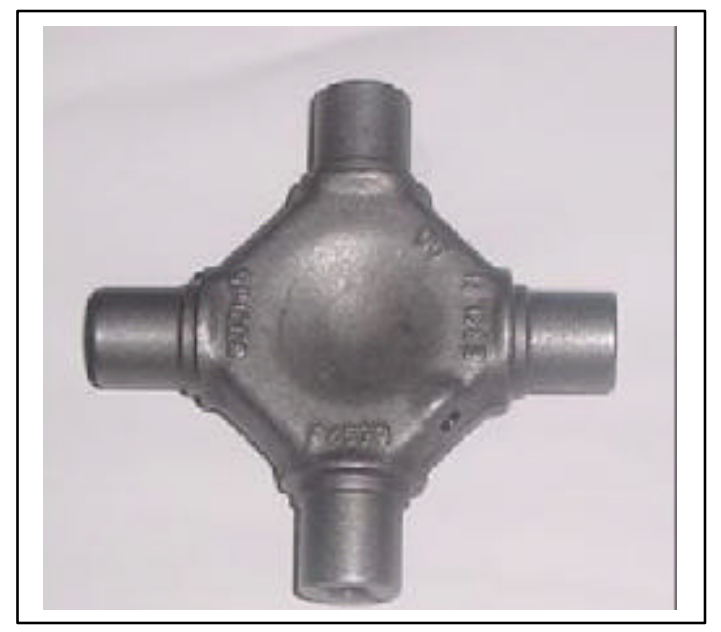

Figure 8. UJ Crosses

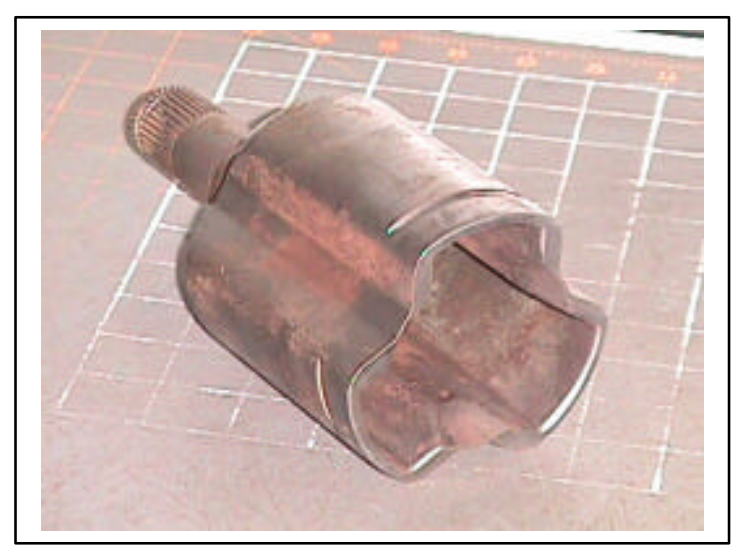

Figure10. Tripot

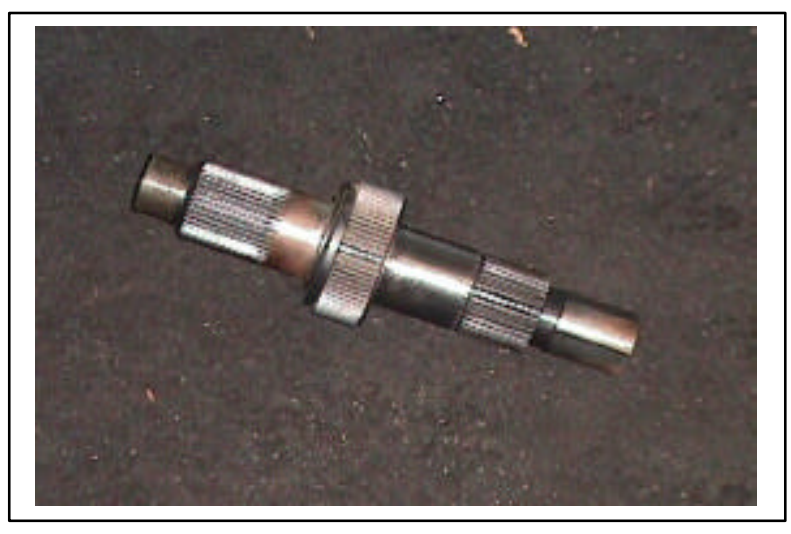

Figure 7. Input Shaft

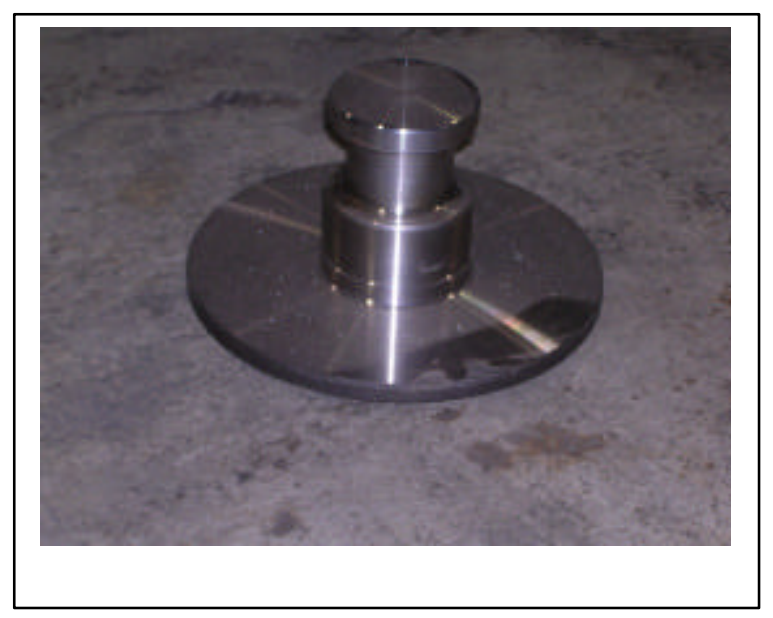

Figure 9. Kingpin

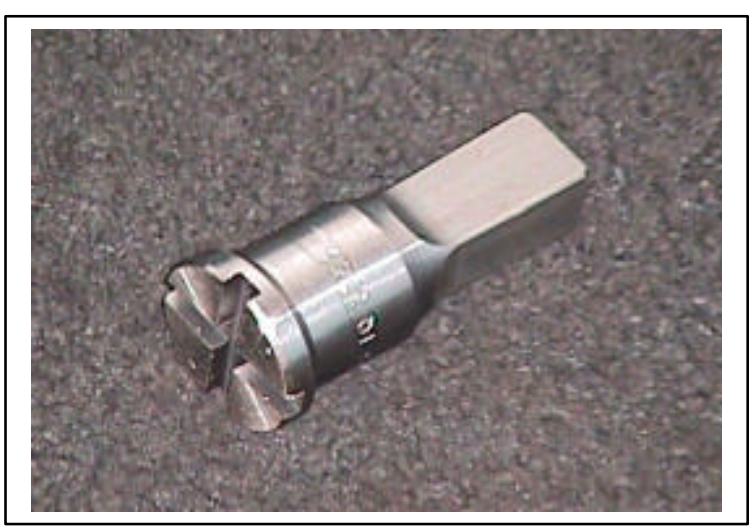

Figure11. Punch 


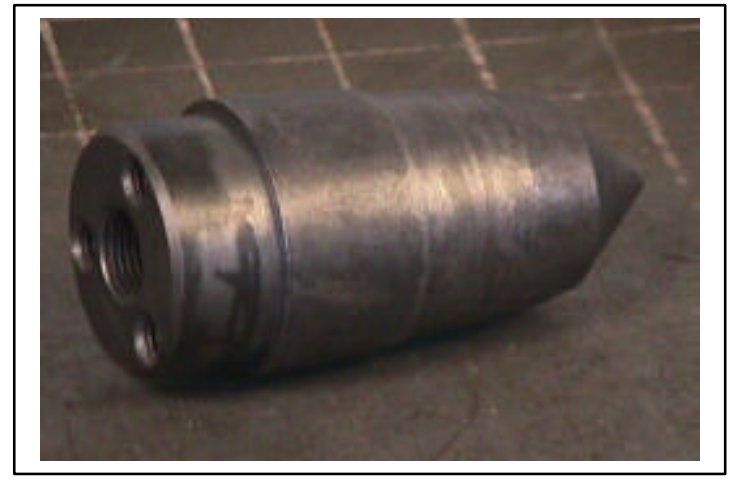

Figure 12. Aluminum Extrusion Die

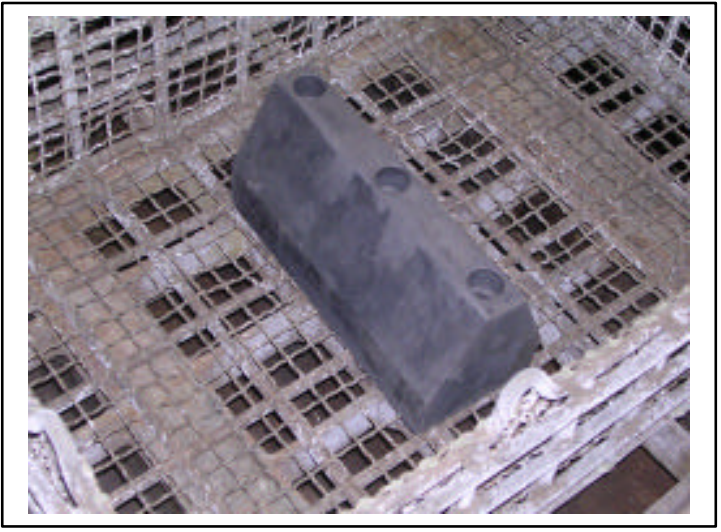

Figure 14. Base Key

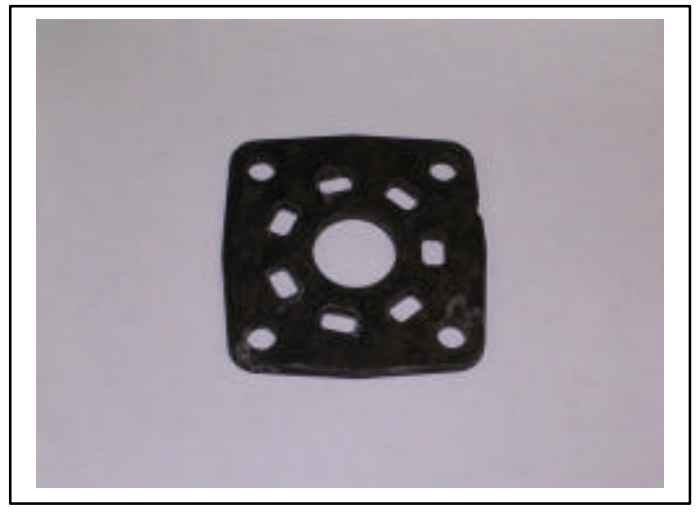

Figure 13. Wear Plate

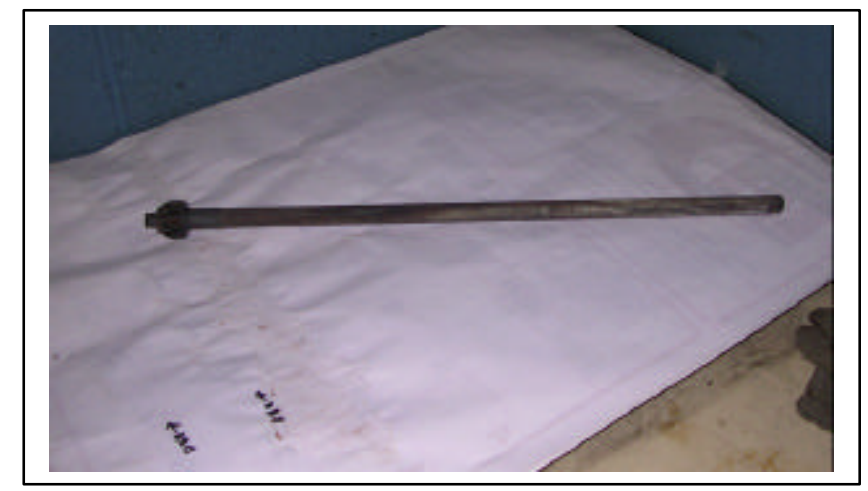

Figure 15. Lawnmower Tractor Shaft

The major achievements from the IQ demonstrations conducted are the following:

$\Rightarrow$ A punch manufacturer that is currently an EHT customer is planning to send all punches for heat treatment to the Center for Intensive Quenching as soon as the new IQ equipment is ready for production runs. The company will also continue a further evaluation of the IQ process for $\mathrm{S} 7$ steel shear blades.

$\Rightarrow$ General Aluminum Manufacturing Co., a member of the project team agreed to heat treat $\mathrm{H}-13$ steel aluminum extrusion dies using the IQ process. We will heat treat the $\mathrm{H}-13$ steel parts in the new IQ system installed at the Center for Intensive Quenching (see Section 3.2).

$\Rightarrow$ After initial favorable metallurgical findings and field-testing, both of the wear plates manufacturers will be sending more parts to EHT for intensive quenching.

$\Rightarrow$ All IQ demonstrations conducted with the parts made of carburized grades of steel showed that the duration of the carburization cycle can be reduced by about $40 \%$ when applying the IQ process. 
Table 3 List of Tested Parts

\begin{tabular}{|c|c|c|c|}
\hline Part Name & Type of Steel & Customer & IQ Equipment \\
\hline \multicolumn{4}{|l|}{ Automotive parts: } \\
\hline Tripots & 4120 carburized & IQT customer & IQ tank, EHT \\
\hline Kingpins & 8630 & EHT customer & IQ tank, EHT \\
\hline Housings & 8620 carburized & EHT customer & IQ tank, EHT \\
\hline Universal Joint Crosses & 5120 carburized & EHT customer & IQ tank, EHT \\
\hline Torsion bars & 4130 & AST customer & IQ tank, AST \\
\hline Coil springs & 9254 & IQT customer & H-V IQ system \\
\hline Leaf springs & 5160 & IQT customer & IQ tank, EHT \\
\hline Axle shaft & 4350 & IQT customer & IQ tank, EHT \\
\hline Input shaft & 5150 & IQT customer & IQ tank, EHT \\
\hline Output shafts & 1050 & IQT customer & H-V IQ system \\
\hline Ring gears & 8620 carburized & IQT customer & IQ tank, EHT \\
\hline Pinions & 8622 carburized & IQT customer & IQ tank, EHT \\
\hline \multicolumn{4}{|l|}{ Tool Products: } \\
\hline Dies & Hot work H-13, 1045 & IQT \& AST customers & IQ tank, AST \\
\hline Cold roll dies & Cold work DC-53 & AST customer & IQ tank, AST \\
\hline Wire cutters & Cold work D2 & IQT customer & IQ tank, AST \\
\hline Punches & Shock-resisting S5 & EHT \& IQT customers & IQ tank, AST \\
\hline Punch holder & 9310 carburized & AST customer & IQ tank, AST \\
\hline Share blade & A8 and S7 & EHT \&IQT customers & IQ tank, AST \\
\hline Chisels & 1070 and 1080 & EHT customer & IQ tank, EHT \\
\hline Hammers & Alloy 4150 & AST customer & IQ tank, AST \\
\hline Tubes & 1010 carburized & EHT customer & IQ tank, EHT \\
\hline Digging teeth & Low carbon low alloy & EHT customer & IQ tank, EHT \\
\hline $\begin{array}{l}\text { Concrete production } \\
\text { wear plates }\end{array}$ & $\begin{array}{l}4140,1045 \text { and } 8620 \\
\text { carburized }\end{array}$ & $\begin{array}{l}\text { IQT and EHT } \\
\text { customers }\end{array}$ & $\begin{array}{l}\text { IQ tanks, AST } \\
\text { and EHT }\end{array}$ \\
\hline Hand tool sockets & $40 \mathrm{~B} 25$ & IQT customer & IQ tank, AST \\
\hline Base keys & 1018 carburized & EHT customer & IQ tank, EHT \\
\hline \multicolumn{4}{|l|}{ Miscellaneous Parts: } \\
\hline Lawnmower tractor shaft & 1010 carburized & AST customer & IQ tank, AST \\
\hline Stampings & 1035 & EHT customer & IQ tank, EHT \\
\hline Gear blanks & 4340 and 4140 & AST customer & IQ tank, AST \\
\hline Marine crankshafts & 8620 carburized & EHT customer & IQ tank, EHT \\
\hline Railroad casting & 4320 & AST customer & IQ tank, AST \\
\hline Gears & Powder metal & IQT customer & IQ tank, EHT \\
\hline Wear pads & 1010 carburized & AST customer & IQ tank, AST \\
\hline \multicolumn{4}{|l|}{ Fasteners: } \\
\hline Pins & 52100 & IQT customer & IQ tank, AST \\
\hline Automotive fasteners & 1010 carburized & AST customer & IQ tank, AST \\
\hline Automotive fasteners & 1055 & AST customer & IQ tank, AST \\
\hline
\end{tabular}




\section{Material Characterization Study}

The significant difference in quench-cooling rates provided by the IQ processes and by conventional quenching methods results in a different microstructure in the parts after intensive quenching and after quenching in oil (Reference 19). Depending on the hardenability of the steel, the steel subjected to the intensive quench will be harder and have a finer structure than the oil or air quenched steel. These differences are greater as the cross-sectional thickness of the part increases. As with conventional quenching, the higher the cooling rate, the better the mechanical properties of the hardened steel part. In contrast to conventional quenching, however, the improvements to part mechanical properties obtained from IQ are not gained at the expense of additional part distortion or cracking.

Over the last several years (Reference 6-16), IQ Technologies Inc and its customers conducted numerous studies of mechanical properties of actual parts that were intensively quenched. The data were compared to the same parts quenched in oil. In all instances, the oil quenched parts and intensively quenched parts were made from the same steel heat and were tempered to the same surface hardness. The intensively quenched parts have shown superior mechanical properties. The data presented in this work, clearly demonstrates that the IQ process significantly improves steel mechanical properties. Another important benefit of the IQ process is that it improves both the part strength and the part toughness at the same time. In addition, the environmental and cost benefits from the elimination of quench oils or quench polymers when using IQ should be noted.

\subsection{Material Characterization Study Procedure}

Case Western Reserve University (CWRU) of Cleveland, Ohio conducted a material characterization study. CWRU considered three groups of steels (through-hardening steels - plain carbon and alloy and carburized steels) and conducted three investigations.

Using the process parameters dictated by the IQ computer model, the first investigation studied the effect of the IQ method on several carbon steels, 1038, 1045 and 1060, compared to four types of commonly used alloy steels, 5160, 4130, 4140 and H13. This investigation compared the tensile and impact properties of these steel types after intensive quenching and after traditional oil quenching processes.

The second area of investigation studied the hardness distribution, case depth and residual surface stresses of various steels after case hardening with a conventional oil quench process, and with the intensive quench process. The results compare the hardness and residual surface stresses of carburized, plain carbon, 1018 steel in the intensively quenched condition, to carburized and oil quenched 4320, 5120 and 8620 (all as tempered at 400F). These results show about the same properties for the intensively quenched 1018 plain carbon steel compared to the three varieties of oil-quenched alloy steels.

The third area of investigation examined the hardness and residual stresses of 52100 throughhardening steel bearing rollers of $46 \mathrm{~mm}$ and $75 \mathrm{~mm}$ diameter. Lambda Technology, Inc. of Cincinnati, Ohio measured the residual stress distribution by determining the X-ray diffraction at every $0.5 \mathrm{~mm}$ interval from the roller surface to a depth of $3.0 \mathrm{~mm}$. The results show a marked increase in the beneficial compressive residual stress for the 52100 steel rollers quenched in highvelocity IQ system versus conventional oil quenching. The maximum residual stress in compression reaches - $838 \mathrm{MPa}$ at the surface of the specimens processed in the high velocity IQ system. The residual compressive surface stresses obtained with the high velocity intensive quench process are compared to those obtained in the "less intensive," batch-type, IQ system. 


\subsection{Improvement of Through- Hardening Steel Mechanical Properties}

The following seven steels: 1038, 1045 and 1060 (plain carbon steels), and 5160, 4130 and 4140 ("oil hardening," alloy steels), and H-13 ("air hardening," high alloy, hot work tool steel) were tested. Small round bars of $\varnothing 19 \mathrm{~mm}$ and $\varnothing 22 \mathrm{~mm}$, large round bars of $\varnothing 35 \mathrm{~mm}$ to $\varnothing 51 \mathrm{~mm}$ and large square bars of $51 \times 51 \mathrm{~mm}$ were investigated. All the above test bars were of $380 \mathrm{~mm}$ in length and from the same heat lot of steel. For each type of steel, the test bars were quenched intensively in water or quenched in oil, then tempered to the same surface hardness. The following steel properties were measured: tensile strength, yield strength, elongation, reduction in area and the impact strength.

After heat treatment, standard tensile sample bars were made from each size test bars of the seven different steels, and a set of V-notch impact samples were produced from the core area of the treated test bars. Depending on the test bar size and on the quenching process employed, different sizes of test bars were used to measure the differences in steel properties in the core of the test sample after quenching and tempering.

Prior to making tensile and impact specimens from the bars, the bars were heat treated in two groups. One set of bars was quenched in oil and the second set of the bars was intensively quenched one-by-one from a neutral salt bath furnace to a high-velocity ("HV") IQ system (Reference 19). Since the bars of H-13 steel must be austenitized at temperatures higher than what the salt bath furnace can provide, they were heated in an atmosphere-controlled furnace before quenching.

The test bars were placed in the IQ system quench chamber and cooled at an "intensive" cooling rate with very rapidly flowing water. The optimum intensive water quenching conditions for the test bars of different sizes were obtained by providing the proper water flow rate through the quench chamber of the IQ system, then interrupting the intensive water quench when the model predicted maximum compressive surface stresses had been obtained. Table 4 presents the calculated cooling rates at the core (for a given core temperature) of each for the test bars of different sizes quenched in the high-velocity IQ system and quenched in the oil tank. The values in Table 4 represent the cooling rate of the core when its temperature is equal to $550^{\circ} \mathrm{C}\left(1,022^{\circ} \mathrm{F}\right)$ -- the point of the austenite minimum stability $\left(500-550^{\circ} \mathrm{C}\right)$. (When conducting the cooling rate calculations, it was assumed that the water temperature was equal to $20^{\circ} \mathrm{C}\left(72^{\circ} \mathrm{F}\right)$ and the quench oil temperature was equal to $50^{\circ} \mathrm{C}\left(122^{\circ} \mathrm{F}\right)$.)

\section{Table 4 Test Bar Calculated Core Cooling Rates}

\begin{tabular}{|c|c|c|}
\hline \multirow{2}{*}{ Bar Size, } & \multicolumn{2}{|c|}{$\begin{array}{c}\text { Core Cooling } \\
\text { Rate @ 550 } \\
\mathbf{}^{\mathbf{0}} \mathbf{C} \text { C/sec }\end{array}$} \\
\cline { 2 - 3 } $\mathbf{m m}$ & IQ & Oil \\
\hline$\varnothing 19$ & 162 & 58 \\
\hline$\varnothing 30$ & 65 & 23 \\
\hline$\varnothing 38$ & 40 & 15 \\
\hline$\varnothing 51$ & 23 & 8 \\
\hline
\end{tabular}

The H-13 steel test bars were quenched intensively in the 6,000-gallon, IQ water tank ("WT") out of an atmosphere furnace capable of austenitizing the H13 material. The water flow velocity in the IQ tank is much lower than that in the high- velocity IQ system used for the other intensively quenched samples. (Note that the IQ conditions for the H13 test bars were not optimized according to the IQT model; without the optimal intensive quenching rate, the maximum improvement in $\mathrm{H} 13$ properties was not obtained. 
In addition it should be noted that the "typical" H13 quench method is gas atmosphere or air quench. The data presented here for "traditional" quenching was obtained with the higher cooling rate of an oil quench.) After intensive quenching or oil quenching, all test bars were tempered to the specified hardness. Table 2 presents the thermal cycles used for quenching and tempering of the above test bars.

Table 5 Thermal Cycles Used For Test Bars

\begin{tabular}{|c|c|c|}
\hline $\begin{array}{c}\text { Type of } \\
\text { Steel }\end{array}$ & $\begin{array}{c}\text { Austenitizing } \\
\text { Temperature }\end{array}$ & Tempering Temperature \\
\hline 1038 & $860^{\circ} \mathrm{C}\left(1,580^{\circ} \mathrm{F}\right)$ & $496^{\circ} \mathrm{C}\left(925^{\circ} \mathrm{F}\right)$ \\
\hline 1045 & $845^{\circ} \mathrm{C}\left(1,550^{\circ} \mathrm{F}\right)$ & $460^{\circ} \mathrm{C}\left(860^{\circ} \mathrm{F}\right)$ \\
\hline 1060 & $845^{\circ} \mathrm{C}\left(1,550^{\circ} \mathrm{F}\right)$ & $399^{\circ} \mathrm{C}\left(750^{\circ} \mathrm{F}\right)$ \\
\hline 5160 & $845^{\circ} \mathrm{C}\left(1,550^{\circ} \mathrm{F}\right)$ & $371^{\circ} \mathrm{C}\left(700^{\circ} \mathrm{F}\right)$ \\
\hline 4130 & $850^{\circ} \mathrm{C}\left(1,560^{\circ} \mathrm{F}\right)$ & $496^{\circ} \mathrm{C}\left(925^{\circ} \mathrm{F}\right)$ \\
\hline 4140 & $850^{\circ} \mathrm{C}\left(1,560^{\circ} \mathrm{F}\right)$ & $440^{\circ} \mathrm{C}\left(825^{\circ} \mathrm{F}\right)$ \\
\hline $\mathrm{H}-13$ & $1,020^{\circ} \mathrm{C}\left(1,870^{\circ} \mathrm{F}\right)$ & $\begin{array}{c}\text { Double tempered at: } 540^{\circ} \mathrm{C} \\
\left(1,000^{\circ} \mathrm{F}\right) \text { and } 600^{\circ} \mathrm{C}\left(1,110^{\circ} \mathrm{F}\right)\end{array}$ \\
\hline
\end{tabular}

The testing of the room temperature tensile properties was conducted in a Baldwin machine where the yield strength and tensile strength were obtained during testing. The ductility was quantified in the bars by determining their elongation and reduction area. The Charpy tests were conducted on all samples in a Tinius Olsen impact machine at room temperature.

As an example, Figure 16 illustrates the significant difference in the microstructure for $\varnothing 19 \mathrm{~mm}$ test bars made of 1045 steel after intensive quenching and after quenching in oil. The significantly finer microstructure in turn, improved the mechanical properties of the steel. The results the tensile properties obtained from these steels are shown in Table 3 for the small diameter test bars of $\varnothing 19 \mathrm{~mm}$ and $\varnothing 22.4 \mathrm{~mm}$. These results show the mechanical properties of the IQ steels (except for oil quenched H13 and 4140) are always higher than the comparable oil quenched steels. Despite the differences in hardness, the ductility of the IQ material is only reduced slightly by the higher hardness level. This means that the majority of the IQ samples were stronger, and, at the same time, more ductile when compared to the oil quenched samples.

The tensile strength results and hardness at the core for the large samples made of six different steels are shown in Table 6. The diameter of the specimens varies from $\varnothing 30 \mathrm{~mm}$ to $\varnothing 51 \mathrm{~mm}$. With the larger samples, the as-tempered hardness of the intensively quenched steel is usually slightly higher than the oil quenched steel. The higher hardness does not come at the expense of the ductility - in fact the ductility is usually somewhat higher for the IQ material. These differences occur because of the better quench of the intensive quench process and the associated finer microstructure compared to the oil quench process.

Generally, the intensively quenched steels have a higher hardness to a greater depth versus the oil-quenched steels, independent of the section size of the specimen. The rapid cooling from the intensive quench provides a higher strength level and also better impact resistance, even at the higher strength levels. The only exception is the oil-quenched H13 steel, with its high hardenability, and the 4140 steel in the small size sample. In these cases, the strength of the oilquenched steel was slightly higher. However, the intensively quench material does have a 


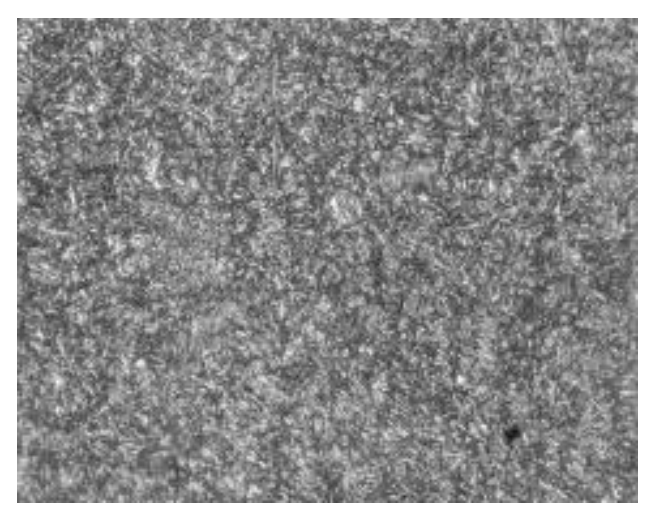

Intensively quenched X250

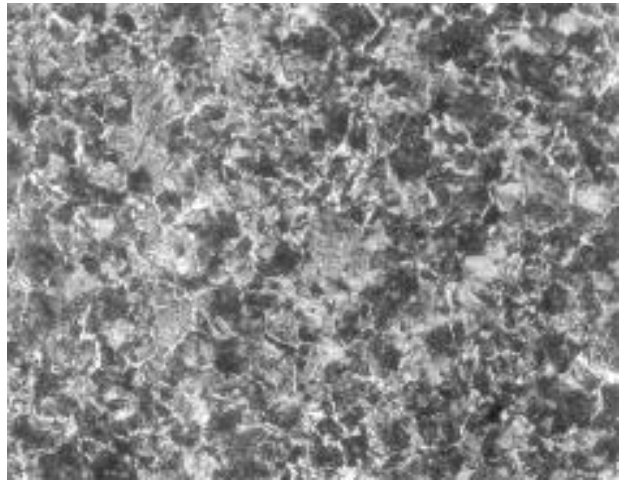

Oil-quenched X250

Figure 16. Microstructure of $\varnothing 19 \mathrm{~mm}$ Test Bars Made Of 1045 Steel

Table 6 Mechanical Properties For Small Test Samples

\begin{tabular}{|c|c|c|c|c|c|c|}
\hline $\begin{array}{c}\text { Test Bar } \\
\text { Cross } \\
\text { Section, } \\
\text { mm }\end{array}$ & $\begin{array}{c}\text { Steel/ } \\
\text { Quench }\end{array}$ & $\begin{array}{c}\text { Core } \\
\text { Hardness, RC }\end{array}$ & $\begin{array}{c}\text { Ultimate } \\
\text { Strength, ksi }\end{array}$ & $\begin{array}{c}\text { Yield } \\
\text { Strength, ksi }\end{array}$ & Elongation, \% & $\begin{array}{c}\text { Reduction } \\
\text { in Area, } \\
\text { \% }\end{array}$ \\
\hline$\varnothing 19$ & 1045 IQ & 37 & 172.6 & 163.0 & 13.3 & 48.3 \\
\cline { 2 - 7 } & 1045 Oil & 32 & 143.2 & 111.0 & 19.0 & 60.2 \\
\hline \multirow{2}{*}{$\varnothing 19$} & 1060 IQ & 44 & 212.3 & 199.6 & 10.8 & 30.6 \\
\cline { 2 - 7 } & 1060 Oil & 40 & 177.9 & 140.0 & 12.2 & 31.6 \\
\hline$\varnothing 22$ & 4130 IQ & 35 & 157.2 & 142.7 & 17.8 & 63.4 \\
\cline { 2 - 7 } & 4130 Oil & 30 & 134.1 & 117.2 & 19.3 & 64.7 \\
\hline$\varnothing 19$ & 4140 IQ & 48 & 195.7 & 163.1 & 13.8 & 52.7 \\
\cline { 2 - 7 } & 4140 Oil & 45 & 218.3 & 171.2 & 12.5 & 48.2 \\
\hline$\varnothing 19$ & 5160 IQ & 48 & 250.4 & 229.6 & 11.5 & 39.5 \\
\cline { 2 - 7 } & 5160 Oil & 47 & 230.7 & 213.3 & 11.7 & 38.2 \\
\hline$\varnothing 19$ & H-13 IQ & 45 & 219.5 & 187.8 & 15.6 & 52.5 \\
\cline { 2 - 7 } & H-13 Oil & 47 & 231.3 & 197.7 & 14.4 & 51.5 \\
\hline
\end{tabular}

Table 7 Mechanical Properties For Large Test Samples

\begin{tabular}{|c|c|c|c|c|c|c|}
\hline $\begin{array}{l}\text { Test Bar Cross } \\
\text { Section, mm }\end{array}$ & $\begin{array}{c}\text { Steel/ } \\
\text { Quench }\end{array}$ & $\begin{array}{c}\text { Core } \\
\text { Hardness, } \\
\text { RC } \\
\end{array}$ & $\begin{array}{c}\text { Ultimate } \\
\text { Strength, } \\
\text { ksi }\end{array}$ & $\begin{array}{c}\text { Yield } \\
\text { Strength, } \\
\text { ksi }\end{array}$ & $\begin{array}{c}\text { Elongation, } \\
\%\end{array}$ & $\begin{array}{c}\text { Reduction in } \\
\text { Area, \% }\end{array}$ \\
\hline \multirow[t]{2}{*}{$\varnothing 30$} & $1038 \mathrm{IQ}$ & 26 & 122.2 & 90.1 & 21.0 & 56.4 \\
\hline & 1038 Oil & 23 & 116.9 & 77.1 & 20.3 & 51.3 \\
\hline \multirow[t]{2}{*}{$\varnothing 50$} & $1045 \mathrm{IQ}$ & 28 & 129,2 & 102.0 & 21.0 & 49.6 \\
\hline & 1045 Oil & 27 & 127.5 & 90.7 & 18.4 & 42.2 \\
\hline \multirow[t]{2}{*}{$50 \times 50$} & $1060 \mathrm{IQ}$ & 38 & 178 & 133.8 & 14.8 & 36.8 \\
\hline & 1060 Oil & 38 & 176.3 & 126.2 & 10.9 & 23.0 \\
\hline \multirow[t]{2}{*}{$\varnothing 50$} & $4140 \mathrm{IQ}$ & 44 & 209.7 & 155.4 & 13.8 & 52.0 \\
\hline & 4140 Oil & 42 & 192.6 & 146.5 & 14.3 & 50.2 \\
\hline \multirow[t]{2}{*}{$\varnothing 38$} & $5160 \mathrm{IQ}$ & 48 & 273.4 & 217.2 & 4.9 & 7.3 \\
\hline & 5160 Oil & 48 & 235.2 & 187.3 & 8.3 & 21.1 \\
\hline \multirow[t]{2}{*}{$\varnothing 50$} & H-13 IQ & 44 & 206.4 & 187.8 & 13.9 & 43.3 \\
\hline & H-13 Oil & 45 & 219.9 & 179.6 & 12.7 & 38.4 \\
\hline
\end{tabular}


significantly higher impact strength as shown in Table 8 and 9. Also as noted above, the intensive quench from the atmosphere furnace used to austenitizing the $\mathrm{H}-13$ samples, was not optimized per the IQT model. Additionally, in most instances, H13 dies are quenched in gas atmosphere or in air, not in oil.

Table 8 Impact Properties For Small Test Samples

\begin{tabular}{|c|c|c|c|}
\hline $\begin{array}{c}\text { Test Bar Cross } \\
\text { Section, mm }\end{array}$ & $\begin{array}{c}\text { Steel/ } \\
\text { Quench }\end{array}$ & $\begin{array}{c}\text { Ultimate } \\
\text { Strength, } \\
\text { ksi }\end{array}$ & $\begin{array}{c}\text { Impact Strength } \\
@ \mathbf{7 2}^{\mathbf{0}} \mathbf{F}, \mathbf{l b} \cdot \mathbf{f t}\end{array}$ \\
\hline \multirow{2}{*}{$\varnothing 19$} & 1045 IQ & 172.6 & 40 \\
\cline { 2 - 4 } & 1045 Oil & 143.2 & 39 \\
\hline \multirow{2}{*}{$\varnothing 19$} & 1060 IQ & 212.3 & 19 \\
\cline { 2 - 4 } & 1060 Oil & 177.9 & 20 \\
\hline \multirow{2}{*}{$\varnothing 22$} & 4130 IQ & 157.2 & 70 \\
\cline { 2 - 4 } & 4130 Oil & 134.1 & 92 \\
\hline \multirow{2}{*}{$\varnothing 19$} & 4140 IQ & 195.7 & 30 \\
\cline { 2 - 4 } & 4140 Oil & 218.3 & 16 \\
\hline \multirow{2}{*}{$\varnothing 19$} & 5160 IQ & 250.4 & 16 \\
\cline { 2 - 4 } & 5160 Oil & 230.7 & 16 \\
\hline \multirow{2}{*}{$\varnothing 19$} & H-13 IQ & 219.5 & 22 \\
\cline { 2 - 4 } & H-13 Oil & 231.3 & 21 \\
\hline
\end{tabular}

Table 9 Impact Properties For Large Test Samples

\begin{tabular}{|c|c|c|c|}
\hline $\begin{array}{l}\text { Test Bar Cross } \\
\text { Section, mm }\end{array}$ & $\begin{array}{c}\text { Steel/ } \\
\text { Quench }\end{array}$ & $\begin{array}{c}\text { Ultimate } \\
\text { Strength, } \\
\text { ksi }\end{array}$ & $\begin{array}{l}\text { Impact Strength } \\
@ 72^{\circ} \mathrm{F}, \mathrm{lb} \cdot \mathrm{ft}\end{array}$ \\
\hline \multirow[t]{2}{*}{$\varnothing 30$} & 1038 IQ & 122.2 & 62 \\
\hline & 1038 Oil & 116.9 & 28 \\
\hline \multirow[t]{2}{*}{$\varnothing 50$} & $1045 \mathrm{IQ}$ & 129,2 & 25 \\
\hline & 1045 Oil & 127.5 & 23 \\
\hline \multirow[t]{2}{*}{$50 \times 50$} & $1060 \mathrm{IQ}$ & 178 & 9 \\
\hline & 1060 Oil & 176.3 & 8 \\
\hline \multirow[t]{2}{*}{$\varnothing 50$} & $4140 \mathrm{IQ}$ & 209.7 & 15 \\
\hline & 4140 Oil & 192.6 & 14 \\
\hline \multirow[t]{2}{*}{$\varnothing 38$} & $5160 \mathrm{IQ}$ & 273.4 & 7 \\
\hline & 5160 Oil & 235.2 & 7 \\
\hline \multirow[t]{2}{*}{$\varnothing 50$} & H-13 IQ & 206.4 & 14 \\
\hline & H-13 Oil & 219.9 & 12 \\
\hline
\end{tabular}




\subsection{Improvement of Case Depth and Residual Surface Compressive Stresses for Carburized Steels}

We also studied the hardness distribution and case depth with the high-velocity ("HV") IQ and the lower-velocity water tank (WT") IQ systems for carburized plain carbon, 1018 material with a diameter of 30mm. This work was directly compared to the hardness of carburized 4320,5120 and 8620 alloy steels that were quenched in oil. All these specimens were soaked at $927^{\circ} \mathrm{C}$ $\left(1700^{\circ} \mathrm{F}\right)$ for 5 hours @ $0.9 \%$ carbon potential and stabilized at $788^{\circ} \mathrm{C}\left(1450^{\circ} \mathrm{F}\right)$ for 30 minutes and cooled in the furnace under protective atmosphere. The 4320, 5120 and 8620 material were reheated to $843^{\circ} \mathrm{C}\left(1550^{\circ} \mathrm{F}\right)$ in an integral quench atmosphere furnace and then quenched in oil. Two of the 1018 specimens were reheated to $860^{\circ} \mathrm{C}\left(1580^{\circ} \mathrm{F}\right)$ in an integral intensive quench atmosphere furnace, and then quenched intensively in the 11,000-gallon, "batch" IQ water tank. Another two 1018 specimens were reheated to $860^{\circ} \mathrm{C}\left(1580^{\circ} \mathrm{F}\right)$ in a neutral salt bath furnace and quenched intensively one by one in the high-velocity IQ system. All specimens then were tempered at $204^{\circ} \mathrm{C}\left(400^{\circ} \mathrm{F}\right)$ for 2 hours in a tempering furnace.

All the case hardened specimens were examined for their effective case depth, hardness distribution (from surface to core), and their microstructures. Both the 1018 specimens quenched in the batch water tank and in the high-velocity IQ systems were selected to measure their residual stress levels. The 8620 material quenched in oil was also selected to measure its residual stress and to compare to the residual stresses in the 1018 specimens. Their residual stresses were measured for 9 points, every $0.2 \mathrm{~mm}$. The data was gathered to determine whether the IQ processes can provide higher residual compressive stresses in parts made of carburized plain carbon steel, compared to the same parts made of carburized alloy steels quenched in oil. If intensively quenched plain carbon steel can be made to perform equally (or better than) the alloy grades quenched in oil, there should be processing efficiencies and cost savings from substituting the plain carbon steel (e.g., ease of cold forming, better die life, lower material cost, environmental benefits from elimination of oil quench).

The hardness distribution over the entire diameter of the specimens is shown in Figure 17 for the carburized plain carbon steel (1018) quenched in the high-velocity ("HV") IQ system and for the batch (water tank - "WT") IQ system, versus the oil quenched, carburized alloy steels (4320, 5120 and 8620). These results show the improved hardness distribution and illustrate possible substitution of carburized and intensively quenched 1018 steel over the carburized and oil quenched alloy steels. (The differences in the core hardness of the material (below the carburized zone) for the plain carbon steel is due to the somewhat lower carbon, $0.18 \% \mathrm{C}$ for the 1018 , compared to $0.21 \%$ for the 4320 and 8620 and $0.20 \% \mathrm{C}$ for the 5120 alloy steels.)

Figure 18 presents the residual stress values in the part surface layer for the specimens made of plain carbon steel 1018 and quenched intensively in the high-velocity IQ system and in the IQ water tank and for the specimen made of alloy 8620 steel quenched in oil. These results show the significantly improved residual surface stress conditions for both intensively quenched test samples compared to the oil-quenched specimen. Note that the specimen quenched in the highvelocity IQ system had the higher residual surface stresses compared to the test sample quenched intensively in the IQ water tank. This is because the high-velocity IQ system provided optimum quench conditions for the specimen while intensive quenching of the test sample in the IQ water tank was not optimum. 


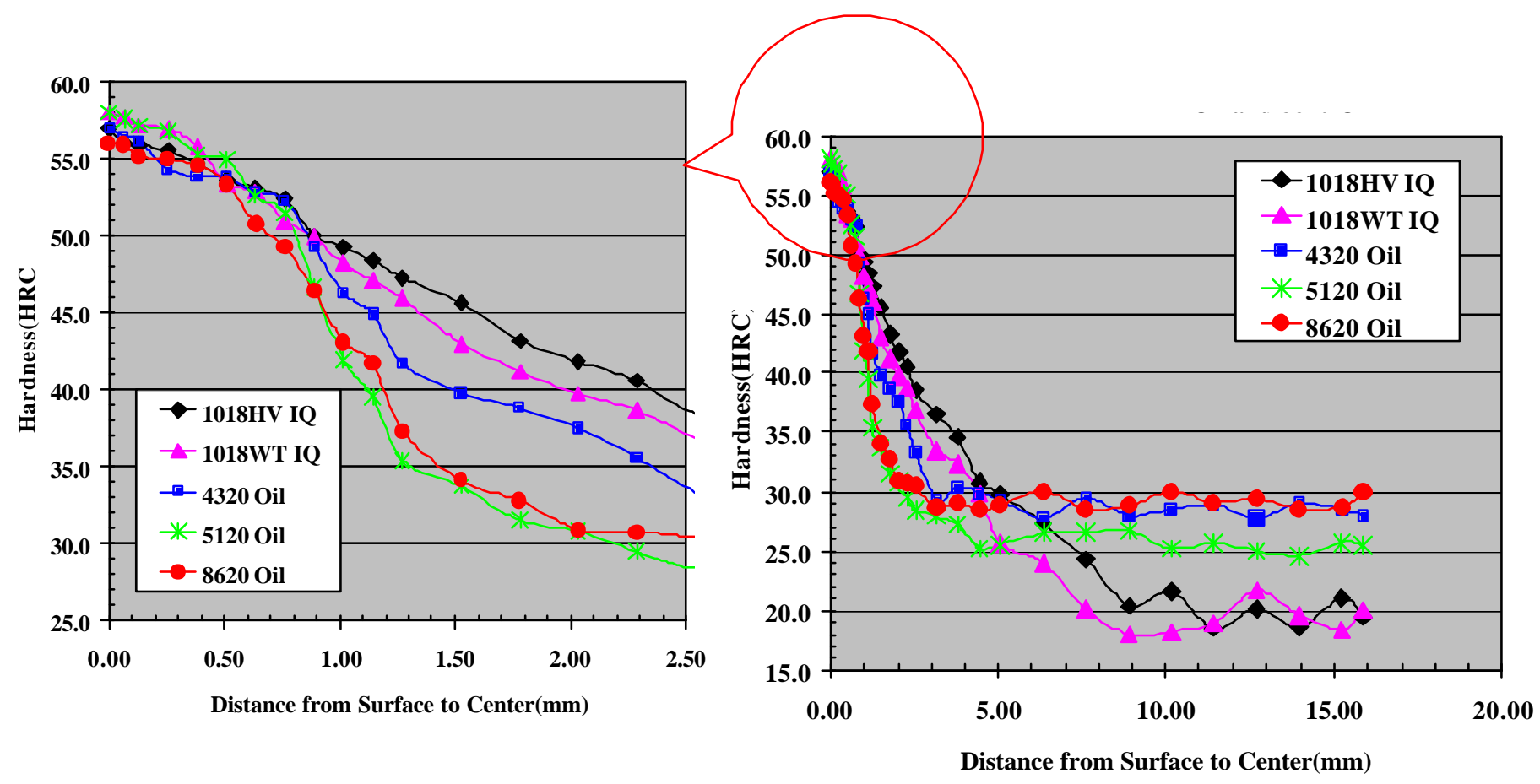

Figure 17. Hardness Distribution Of Carburized 1018, 4320, 5120 And 8620 Steels

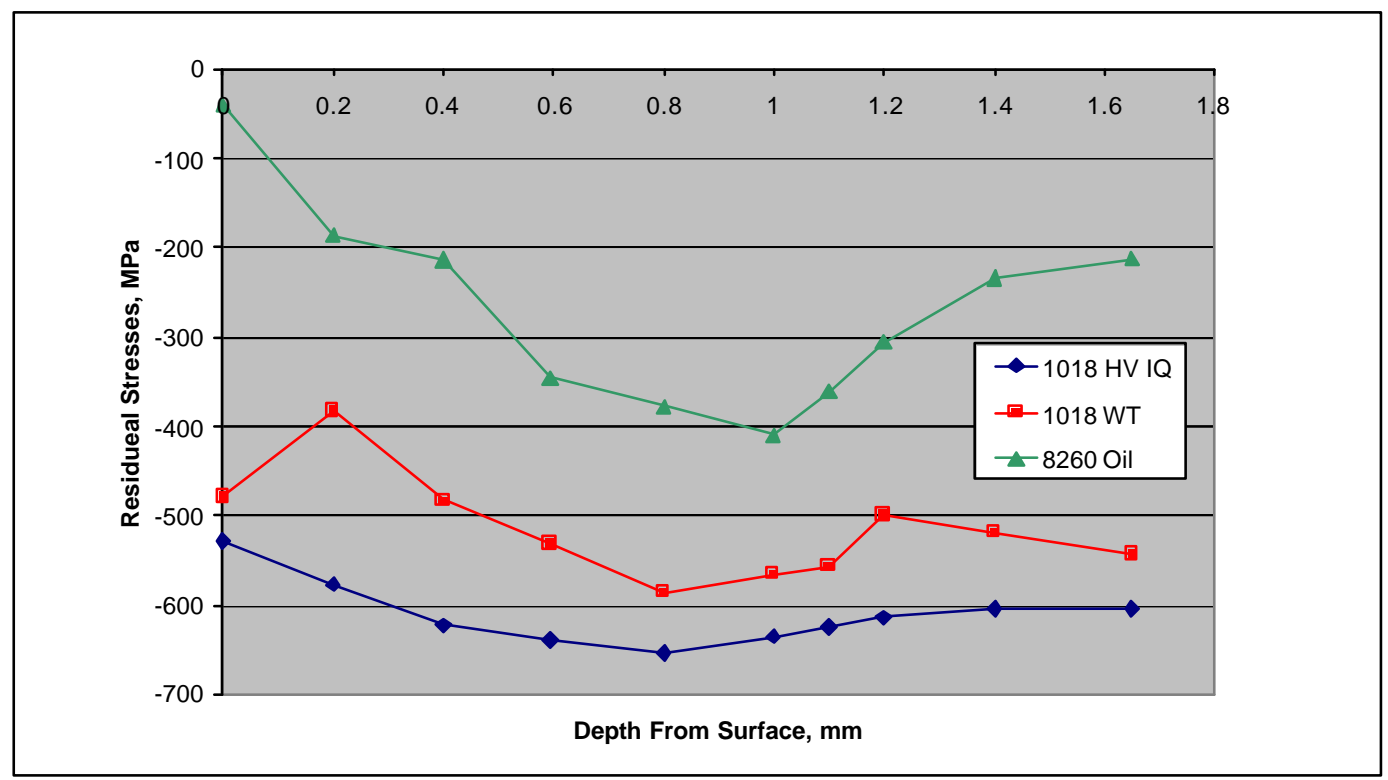

Figure 18. Residual Surface Stress Distribution of Carburized 1018 and 8620 Steels 


\subsection{Improvement of Residual Stress Conditions for Through-Hardening 52100 Bearing Steel}

This investigation determined the hardness distribution and residual stress properties for $46 \mathrm{~mm}$ and $75 \mathrm{~mm}$ diameter, 52100 steel rollers quenched in the high-velocity ("HV") IQ system and the lower-velocity, water tank ("WT") IQ system. The 51200 steel specimens were heated to $843^{\circ} \mathrm{C}$ $\left(1550^{\circ} \mathrm{F}\right)$ for 3 hours and 2 hours for $75 \mathrm{~mm}$ and $46 \mathrm{~mm}$ specimens, respectively, and then quenched intensively in the 11,000-gallon batch IQ water tank or the high-velocity IQ system. All specimens were then tempered at $182^{\circ} \mathrm{C}\left(360^{\circ} \mathrm{F}\right)$ for 2 hours in a tempering furnace. The testing determined the hardness distribution of 52100 steel obtained with the high-velocity and water tank IQ system. The hardness was measured for the surface hardness at both ends at several points per end, and for the circumferential surface hardness at three levels with 16 points per level for the larger $\varnothing 75 \mathrm{~mm}$ specimens and 12 points per level for the smaller $\varnothing 46 \mathrm{~mm}$ specimens. The residual stress was measured for 7 points every $0.5 \mathrm{~mm}$ for $\varnothing 75 \mathrm{~mm}$ specimens, and 6 points every $0.5 \mathrm{~mm}$ for the $\varnothing 46 \mathrm{~mm}$ specimens. This work was done to examine whether the IQ process provides bearing rollers made of 52100 steel with high residual compressive stresses to depths that are comparable to deep-case, carburized rollers made of traditional alloy steel grades (e.g. 8620).

The 52100 steel processed in high-velocity IQ system had the higher compressive residual stresses for both the small and large diameter specimens compared to quenched in the batch type, "lower-velocity" water tank, IQ system. These results are shown in Figure 19. The higher compressive residual stresses were obtained from the larger diameter specimens. The as tempered hardness distribution of this material is relatively uniform at the surface approximately $61.5 \mathrm{HRC}$ to $62.5 \mathrm{HRC}$. The hardness distribution from surface to core is shown in Figure 20.

Based on the above results of the material characterization study, the following conclusions have been made:

$\Rightarrow$ For a given type of steel of the same section size, the intensively quenched steel specimens generally develop a higher strength, and, at the same time, a higher ductility than the steel samples quenched in oil.

$\Rightarrow$ The impact properties obtained from intensively quenched steels are generally superior to the impact properties from oil-quenched steels.

$\Rightarrow$ While the strength level varies depending on the section size and type of steel, because of the rapid cooling rate obtained at the surface of the part and the finer microstructure obtained throughout the part section, the intensively quenched material does exhibit better mechanical properties than the oil quenched material.

$\Rightarrow$ For carburized grades of steel, the intensive quenching process provides both the higher effective case depth and the greater and deeper residual surface compressive stresses.

$\Rightarrow$ The intensively quenched specimens made of plain carbon steel showed deeper effective case depth and higher residual surface compressive stresses than the specimens made of alloy carburized grades and quenched in oil.

$\Rightarrow$ For through hardened steel test rollers, the compressive residual stresses below the surface were the highest for the samples given the high-velocity intensive quench process. These residual stresses extended under the surface to a depth of 2.5 to $2.9 \mathrm{~mm}$. 


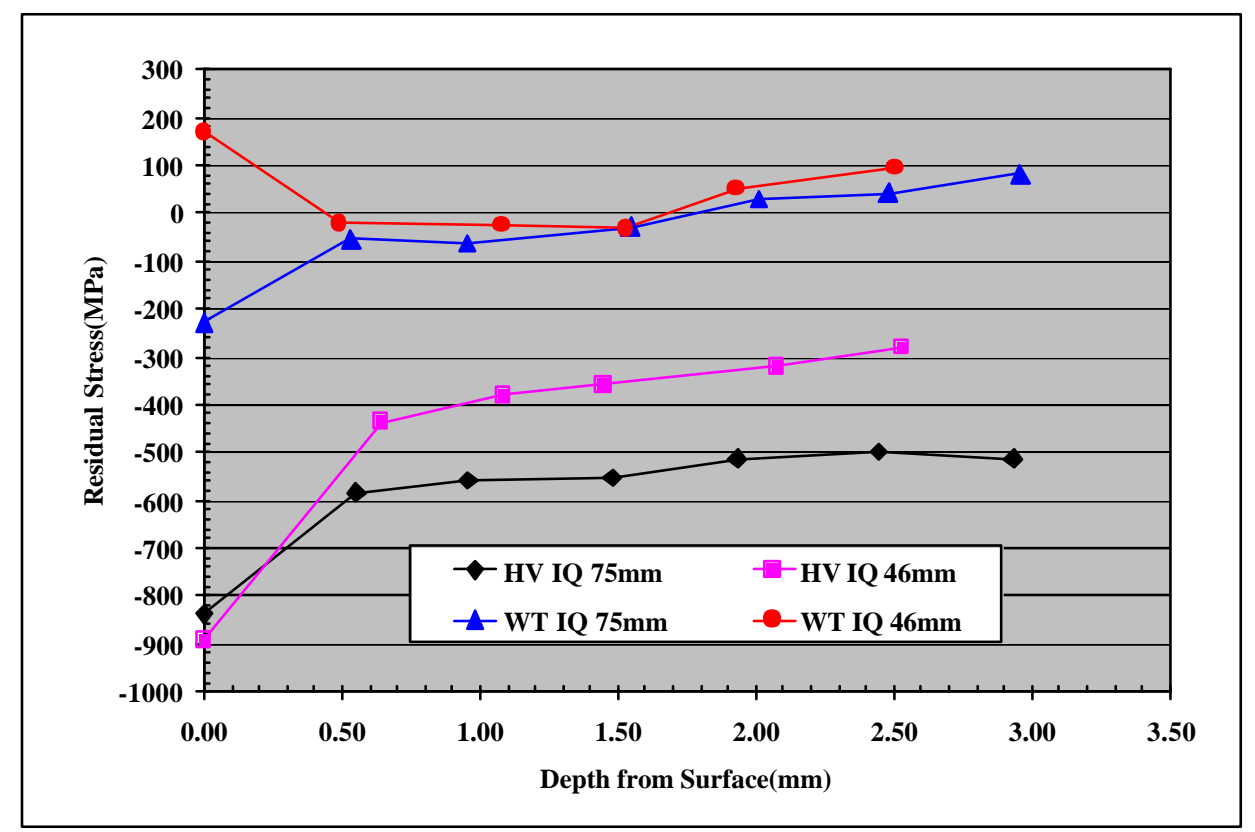

Figure 19. Residual Stress Distribution For 52100 Steels

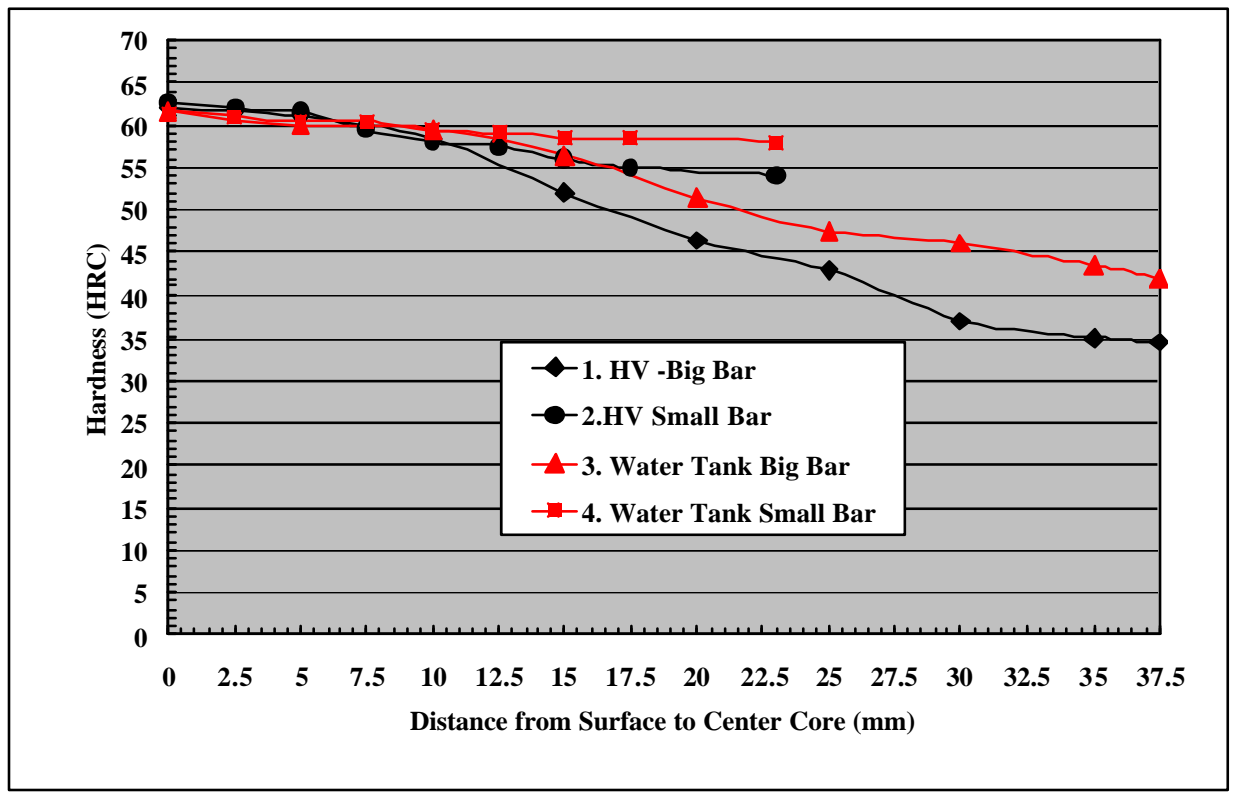

Figure 20. Hardness Distribution of 52100 Steel 


\subsection{Recommendations for Establishing New IQ Standards}

It is apparent from the results of our investigation that the use of intensive water quench has a number of advantages over traditional oil quench methods. As shown in when the results of the IQ water quench over oil quench in paragraph 5.2 are compared, the improvement in strength and toughness are clear. The intensive water quench provided higher properties for all of the processed materials compared to the conventional oil quench. Currently, the Metal Fasteners Industry does not allow "water quenching," due to traditional water quenching's non-uniform cooling causing part distortion and cracking. However with intensive water quenching, the intensity of the quench makes it "uniform" and eliminates the distortion and cracking issues. In addition, part properties could be substantially improved with the new IQ quench with water. Furthermore, the environmental and cost savings benefits from the elimination of quench oils enhance the case for allowing intensive water quenching methods to be used for fasteners. For these reasons, we have requested that the Industrial Fastener Industry's specifications that prohibit "water quenching" be amended to allow "intensive" quenching using water. 


\section{Commercialization of Intensive Quenching Technology}

The objective of this task $f$ the project was to accelerate the commercialization of the IQ technology. We commercialized the IQ technology through the following activities:

$\Rightarrow$ By organizing and conducting IQ workshops at IQT's and customers' facilities

$\Rightarrow$ By participating in exhibitions and technical conferences

$\Rightarrow$ By communicating IQ technology through technical journals and magazines, etc.

Over the course of the project, we have conducted a total of five IQ workshops. We ran one IQ workshop at the Euclid Heat Treating Co. facilities for AFC-Holcroft sales representatives (AFCHolcroft, Inc. is a major heat treating equipment manufacturer in U.S. and a licensee of the IQT). We conducted three IQ workshops at captive heat-treating facilities (Delphi Saginaw Steering Systems of Saginaw, Michigan, GM Powertrain of Ypsilanti, Michigan and ArvinMeritor Heavy Vehicle Systems, of Detroit, Michigan) and one workshop for fasteners manufacturers at their annual Standard Committee meeting that took place in Cleveland, Ohio. We have also scheduled a workshop at American Axle Manufacturing Co. of Detroit, Michigan for October 2005.

We participated at three exhibitions (2003 Furnace North America and 2003 and 2005 ASM Heat Treat Shows). We presented two technical papers to the $22^{\text {nd }}$ ASM 2003 Heat Treating Conference in Indianapolis, Indiana (References 17 and 18) and two technical papers to the $23^{\text {rd }}$ ASM 2005 Heat Treating Conference in Pittsburgh, Pennsylvania (References 21 and 22). We also published a paper in the Material World magazine being issued in England (Reference 20).

Over the course of this project, we introduced the IQ technology in heat-treatment practices of two commercial heat-treating shops: the Akron Steel Treating Co. (AST) of Akron, Ohio and Euclid Heat Treating Co. (EHT) of Cle veland, Ohio.

\subsection{Introduction of IQ Process at Akron Steel Treating Company}

As mentioned in Section 3, AST has one production 6,000-gallon IQ water tank that is equipped with an atmosphere Surface Combustion furnace. As a part of this project, AST has fully automated the IQ water tank and modified the load lifting mechanism to reduce the time required for loading/unloading the parts during intensive quench. AST developed also a standard procedure for controlling a concentration of the sodium nitrite in the IQ water tank, a water temperature and a rate of the quenchant agitation. A full automation of the IQ water tank and a precise control of the quench parameters allow intensive quenching of a variety of steel products in the production IQ system.

AST runs several jobs from three its customers on continuous basis. These jobs are the following:

$\Rightarrow$ Gear blanks made of alloy 4140 and 4340 steels for manufacturing rack and pinion gears

$\Rightarrow$ Shafts made of 1022 carburized steel for lawnmower tractors

$\Rightarrow$ Stampings made of 1022 carburized steel

As an example, Figure 21 shows a production load of lawnmower tractor shafts ready for carburization and intensive quenching. The carburization cycle for these parts was reduced by $40 \%$ while the furnace production rate increased by $30 \%$. A similar reduction of the carburization cycle and an increase of the furnace productivity were achieved for the above 


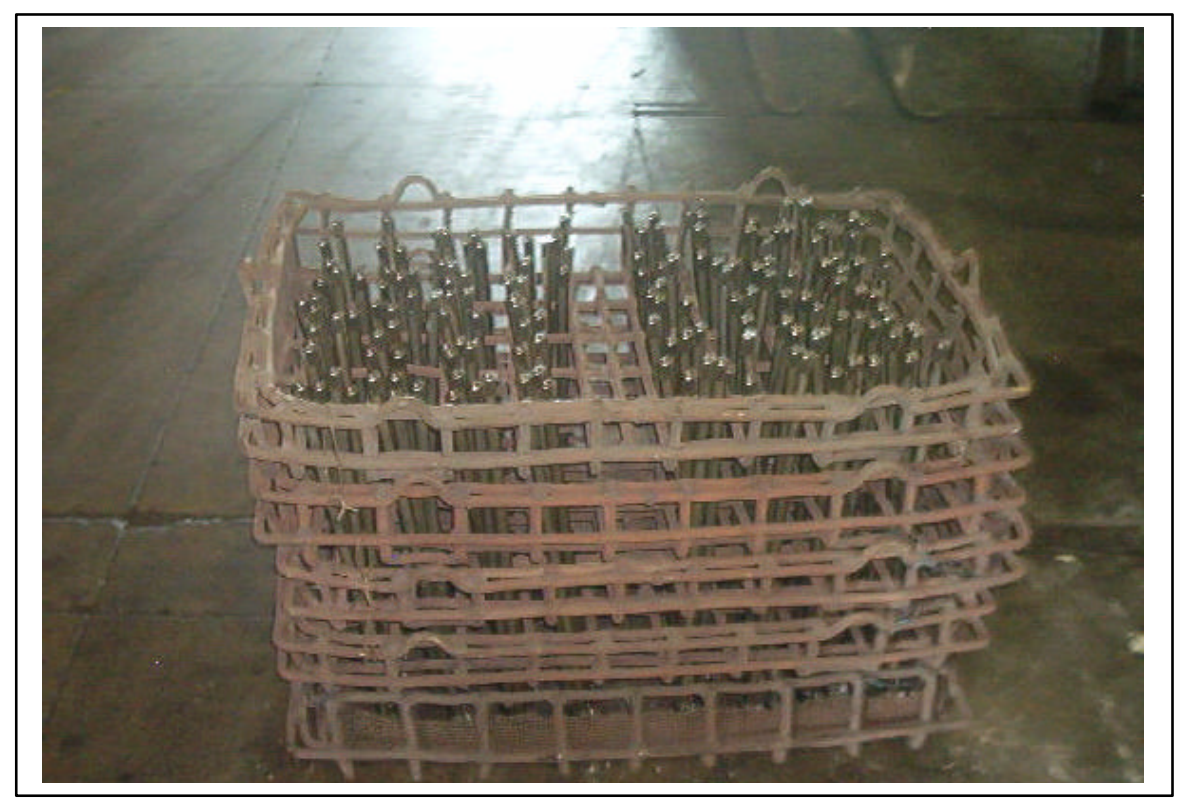

Figure 21. Production Load with Lawnmower Tractor Shaft

stampings for valve body laminations. Implementation of the IQ process for the gear blanks consistently improved the material mechanical properties over traditional oil quenching, allowing the customer to meet the rigid specifications for the mid-radius of the gear blanks.

\subsection{Introduction of IQ Process at Euclid Heat Treating Company}

Euclid Heat Treating Co. bought its first IQ production unit from AFC-Holcroft, Inc. in 2003. It is a three-chamber, integral quench, batch-type furnace with working dimensions of $91 \mathrm{~cm} \times 91 \mathrm{~cm} \times 183 \mathrm{~cm}(36$ " $\times 36$ " $\times 72$ ") for implementing the batch IQ process. Note, that when using an in integral quench type furnace with the water quench tanks, one of the major issues is a possibility of contamination of the furnace protective atmosphere by minute amounts of water or water vapor coming from the quench tank into the furnace heating chamber. This may happen while inner furnace door is open and the load is moved from the furnace to the quench tank or even when the door is closed by migration around the door. To solve this problem, the AFCHolcroft Co. proposed a three-chamber design approach similar to their integral, atmosphere to salt austquenching system.

As seen from the Figures 22 and 23, the AFC/IQ unit has three chambers; a heating chamber, an intermediate chamber, and the quench tank chamber. The intermediate chamber and the quench chamber are constantly ventilated (purged) to the outside air. The furnace chamber and the vestibule over the quench tank both have "leaking" doors; therefore the furnace protective atmosphere gases are continuously flowing from the heating chamber, then entering the intermediate chamber and then flowing out over the water quench tank, creating a buffer between the quench tank and the furnace. When the load starts moving from the heating chamber of the furnace into the intermediary chamber, the quench chamber door is closed. After the load leaves the furnace, the furnace door is closed and the intermediate chamber door to the quench chamber is opened. Thus, the water vapors have no chance to enter the furnace hot zone and destroy the integrity of the protective atmosphere of the heating chamber. 


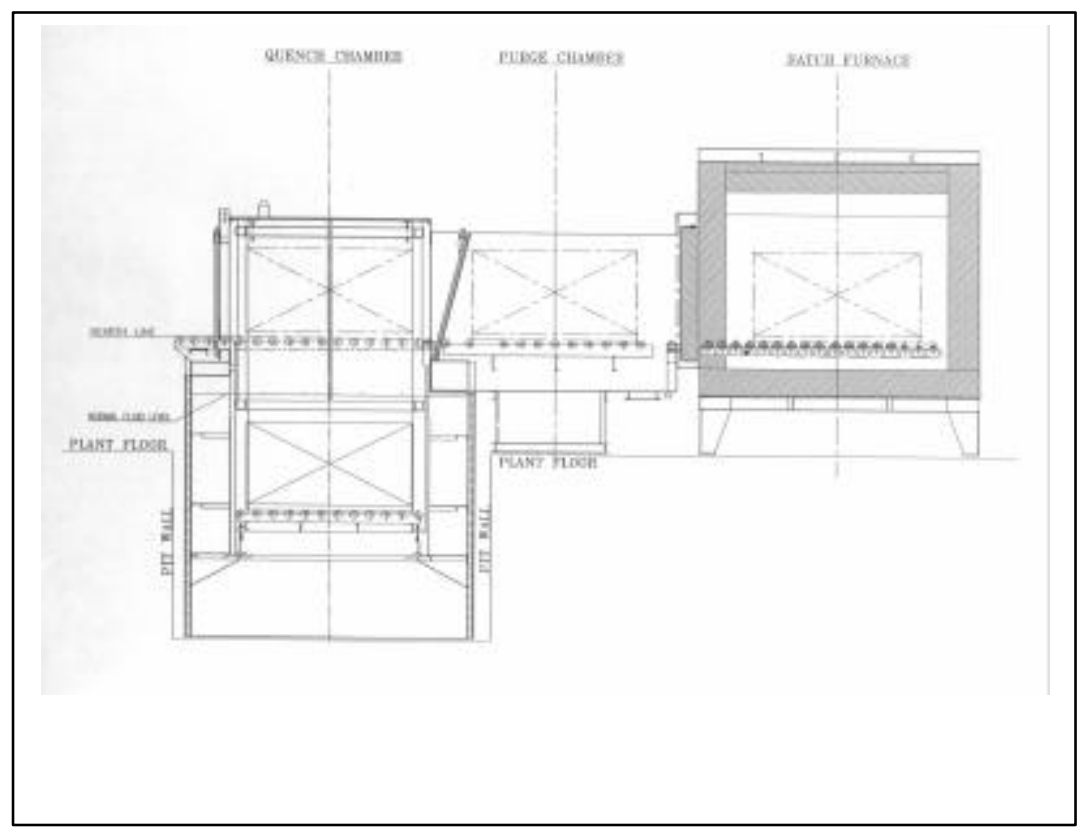

Figure 22. Layout of Production IQ System Installed at Euclid Heat Treating Co.

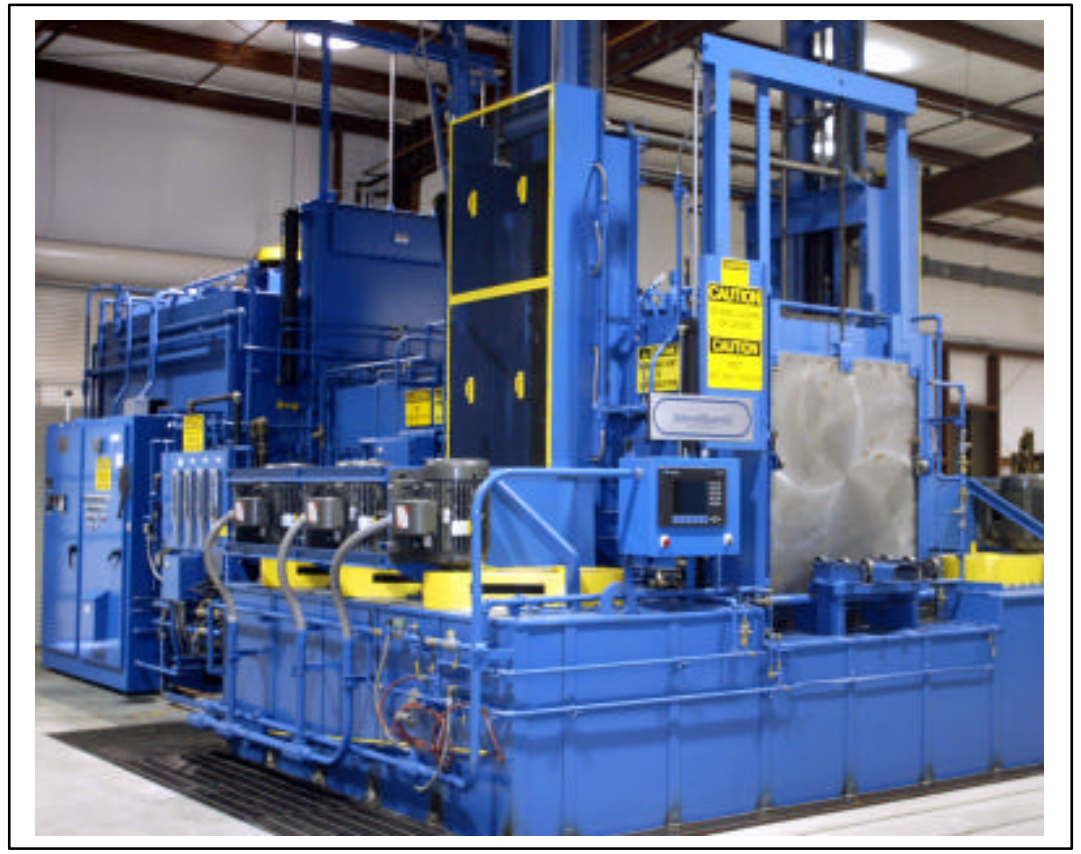

Figure 23. Picture of Production IQ System Installed at Euclid Heat Treating Co. 
IQ Technologies, Inc. provided AFC-Holcroft with technical guidelines for designing the IQ water tank (the size of the tank, number of props and their characteristics, prop location, baffles design, etc.). The $39.7 \mathrm{~m}^{3}$ (11,000-gallon) quench tank is equipped with four $61 \mathrm{~cm}(24$ ") propellers that are rotated by four motors providing a total recirculation of $5.67 \mathrm{~m}^{3} / \mathrm{sec}(90,000$ gpm). The approximate velocity of the quenchant in the tank is be about $1.6-1.8 \mathrm{~m} / \mathrm{sec}(5-6$ $\mathrm{ft} / \mathrm{sec}$ ) passed the parts. Internal direction vanes and baffles provide a uniform quenchant flow velocity through the workload.

The quenching chamber is equipped with a unique lifting mechanism that provides accelerated vertical motion (about 2 seconds) into and out of the quench tank. Minimizing this motion time is very important for accurately implementing IQ cooling recipes.

The new integral quench furnace is equipped with a chiller to maintain the water temperature in the tank $65-70^{\circ} \mathrm{F}$. We also added a sodium nitrite salt to the water to minimize the film-boiling mode of heat transfer during quenching (minimizing the duration of any film boiling in-turn reduces part distortion). The salt concentration in water is about 8 to $10 \%$ that is optimum for the parts processed in this furnace and helps prevent corrosion of the quench tank system.

We conducted a cooling uniformity survey in the 11,000-gallon IQ water tank a number of test samples placed in the load. It was proven that the full-scale intensive quenching system provides a uniform and intensive quenching of up to 2,500-pound batches of steel parts.

Euclid Heat Treating Co. has trained personnel to run its IQ equipment. Also, EHT developed and introduced a standard procedure for controlling a concentration of the sodium nitrite in the IQ water tank, a water temperature and a rate of the quenchant agitation.

Over the course of the project, we conducted a number of IQ demonstrations in the above furnace (see Table 3 in Section 4) above. As an example, Figure 24 shows a production load of base keys ready for carburization and intensive quenching. The carburization cycle for these parts was reduced by $40 \%$ while the furnace production rate increased by $30 \%$. A similar reduction of the carburization cycle and an increase of the furnace productivity were achieved for other products carburized and quenched intensively in this furnace.

\subsection{Further Commercialization of IQ Process}

We are currently working on further commercialization of the IQ method throughout the heattreating industry. Due to the DOE and EMTEC support of this project, we were able to design and built the Center for Intensive Quenching. This was a great step towards the acceleration of the IQ commercialization process. The Center for Intensive Quenching will be a major tool for IQ process demonstrations. The Center includes basically all types of IQ equipment and allows us to validate the IQ processes on an industrial scale for a variety of steel products including high-temperature tool steels. However, the wide commercialization of the IQ process is still facing the following barriers:

$\Rightarrow$ No industrial (captive) installations of IQ systems in the USA

$\Rightarrow$ Lack of steel properties database on many steel types - database is needed for conducting computer simulations that will optimize the compressive stresses while minimizing distortion.

$\Rightarrow$ Limited capabilities in education/promotion of the IQ technology - an intensive quenching process is not currently taught in any metallurgical curriculum in the USA [Dr. Kobasko and Dr. George Totten are currently "writing the book" on intensive quenching methods and practices. The American Society of Materials International (ASM) is planning to publish the book in 2006.]

We need also to develop new standards for heat treatment of steel parts that include the use of the IQ methods. Commercial heat treaters usually process materials according to specifications 
established by the part designer - their customers, or in some cases, their customers' customers. All these generally recognized standards published by organizations such as SAE, SME, ASTM, AISI, the Department of Defense, etc. do not include the intensive water quenching processes.

Developing standards for IQ will require that these organizations be provided with a comprehensive body of data from simulations and actual production part testing that clearly demonstrates the benefits of the technology to increase part performance, to lower part costs, and to eliminate the hazards and pollution from traditional oil quenching methods.

IQT also needs to generate mechanical and thermal property database for a wider variety of steels by conducting extensive material characterization studies. Note that this database can be used for performing computer simulations of material characterizations, as well as, for calculations of part cooling recipes. Some of this data has been presented in Chapter 5 of this final report.

To successfully proceed with the commercialization of intensive quenching technology, we will continue seeking additional financial support from various governmental agencies (DOE, DOD, etc.) in the following areas:

$\Rightarrow$ In conducting IQ demonstrations at our Center for Intensive Quenching as well as in the production IQ systems installed at AST and EHT companies.

$\Rightarrow$ In designing and building pre-production IQ systems for our customers' parts for which we have already proven the IQ technology benefits.

$\Rightarrow$ In helping our customers to install production IQ systems in their facilities. Planting such "seeds" in big U.S. companies (such as Dana Corp., ArvinMeritor, Inc., Delphi Co., Timken Co., etc.) The growth of these seeds is extremely important since the large manufacturers have hundreds of plants where this technology can be effectively used, saving millions of gallons of quench oil per year and reducing or eliminating energy intensive carburization cycles.

$\Rightarrow$ By conducting more IQ workshops at our facilities and at customers' facilities, IQT can educate the wider metallurgical community on the many proven benefits of intensive water quenching, as well as, reduce the time lag between the first "demonstration" phase and the actual adoption of intensive quenching practices into production. 


\section{Project Economic, Energy and Environmental Benefits}

As mentioned in Section 1.1, the IQ technology provides the following energy saving and economic benefits to the overall domestic industry:

$\Rightarrow$ Energy savings and increased productivity of heat-treating equipment due to elimination or shortening of the carburization cycle

$\Rightarrow$ Energy savings due to the use of the part residual heat after forging is completed

$\Rightarrow$ Reduction of the cost of heat-treating operations due to the energy savings, increased furnace productivity and reduced part distortion

$\Rightarrow$ Cost reduction of forging, metal casting, and other operations with steel products due to improved tooling service life (dies, die components, punches, etc.)

$\Rightarrow$ Products with improved quality and performance characteristics (better metal hardness, strength, wear resistance, and service life, lighter but yet stronger product, etc.)

$\Rightarrow$ Stronger and lighter steel parts

We evaluated the IQ process benefits only for the Heat Treating Industry, since data on production rates and energy consumption are available for this industry. We considered two business cases: Case \#1 - savings due to elimination or shortening of the carburization cycle, and Case \#2 - savings due to the part weight reduction.

\subsection{Savings Due to Complete Elimination or Reduction of Carburization Cycle}

The results of IQ demonstrations conducted over the last several years as well as within the time frame of this project have proved that when applying the IQ process the carburization cycle can be either fully eliminated (for example, Reference 15) or significantly reduced (for example, Reference 17). These results showed also that, for economical evaluation, it could be conservatively assumed that the total carburization cycle is reduced by $30 \%$ when using the IQ technique. A complete elimination or reduction of the carburization process results in the reduction of energy consumption, increased furnace productivity and elimination of quench oil. In this report, we evaluated savings for both: per one heat-treating furnace and for the whole Heat Treating Industry.

7.1.1 Saving Per One Heat-Treating Furnace. We considered two types of heat-treating operations: batch and continuous. For batch operations, we considered a typical integral quench atmosphere furnace of 36 "x36"x72". For continuous operations, we considered a typical pusher type furnace of $2,000 \mathrm{lb} / \mathrm{hr}$ production rate. Both types of furnaces are widely used in HeatTreating Industry. Table 10 presents the assumptions we made for an evaluation of the IQ process effectiveness per one heat-treating furnace. We used the following data: a) average values of furnace operation times and production rates provided by the AFC-Holcroft, Inc., a major heat-treating equipment manufacturer in U.S.A., and b) actual data on the reduction of the carburization cycle and on savings from the elimination of oil from Akron Steel Treating, Summit Heat Treating and Euclid Heat Treating companies (the participants of the this project).

Tables 11 and 12 present the results of savings calculations per heat-treating furnace. As seen from these data, annual savings from a typical integral quench atmosphere furnace of 36 "x36"x72" will be about $\$ 158,000$ due to an increase of the furnace production rate, elimination of oil and reduction of energy consumption. The reduction of the natural gas consumption will results in the reduction of $\mathrm{CO} 2$ emissions from burning natural gas and from the gas generator of 35.1 tons per year. For a continuous furnace of 2,000-lb/hr production rate, annual savings will be about $\$ 352,000$, while the reduction of $\mathrm{CO} 2$ emissions will be about 233 tons. 
Table 10 Assumption Made for Evaluation of IQ Process Effectiveness Per One Furnace

\begin{tabular}{|l|l|}
\hline \multicolumn{1}{|c|}{ Parameter } & \multicolumn{1}{|c|}{ Value } \\
\hline Batch 36"x36"x72" heat treating furnace operation time cost & $\$ 75 / \mathrm{hr}$ \\
\hline Continuous 2,000 lb/hr furnace operation time cost & $\$ 150 / \mathrm{hr}$ \\
\hline Annual furnace operation time (two shifts) & $6,000 \mathrm{hr}$ \\
\hline Batch furnace production rate & $300 \mathrm{lb} / \mathrm{hr}$ \\
\hline Continuous furnace production rate & $2,000 \mathrm{lb} / \mathrm{hr}$ \\
\hline Reduction of carburization cycle & $30 \%$ \\
\hline Savings from elimination of oil & $0.5 \mathrm{cent} / \mathrm{lb}$ \\
\hline
\end{tabular}

Table 11 Annual Savings Per Integral Quench Furnace of 36"x36"x72"

\begin{tabular}{|l|l|}
\hline \multicolumn{1}{|c|}{ Parameter } & \multicolumn{1}{|c|}{ Savings } \\
\hline Increased furnace productivity due to reduction of carburization cycle & $\$ 135,000$ \\
\hline Elimination of oil & $\$ 9,000$ \\
\hline Reduction of natural gas consumption & $\$ 4,200$ \\
\hline Total: & $\$ 158,000$ \\
\hline Reduction of $\mathrm{CO}_{2}$ emissions from burning natural gas and from gas generator & 35.1 tons \\
\hline
\end{tabular}

Table 12 Annual Savings For Continuous Furnace With 2,000 Lb/Hr Production Rate

\begin{tabular}{|l|l|}
\hline \multicolumn{1}{|c|}{ Parameter } & \multicolumn{1}{|c|}{ Savings } \\
\hline Increased furnace productivity due to reduction of carburization cycle & $\$ 270,000$ \\
\hline Elimination of oil & $\$ 60,000$ \\
\hline Reduction of fuel consumption & $\$ 22,320$ \\
\hline Total: & $\$ 352,320$ \\
\hline Reduction of $\mathrm{CO}_{2}$ emissions from burning natural gas and from gas generator & 233.4 tons \\
\hline
\end{tabular}

7.1.2 Savings for Heat-Tre ating Industry. To evaluate savings for the whole Heat-Treating Industry, we made the following conservative assumptions based on the available information from the American Society for Materials (ASM), Gas Technology Institute of Chicago, Illinois and other organizations as well as from a numerous discussions with industry experts:

$\Rightarrow$ Heat Treating industry adds about $\$ 15$ billion per year in value to metal goods by imparting specific properties to heat-treated parts

$\Rightarrow$ Heat Treating industry processes about 50 billion pounds of parts per year

$\Rightarrow$ About $80 \%$ of heat-treated parts are made of steel

$\Rightarrow$ About $20 \%$ of steel heat-treated parts are carburized and quenched

$\Rightarrow$ Due to the use of the IQ process, the carburization cycle can be eliminated for $10 \%$ of parts being carburized

$\Rightarrow 1,500$ Btu per pound of parts are required for the carburization process

$\Rightarrow 750$ Btu per pound of parts are required for the through-hardening (IQ) process

$\Rightarrow$ The difference in cost between performing the carburization cycle with following quenching and just the quenching operation is about $\$ 0.25$ per pound 
The total weight of steel parts being heat-treated annually is 50 billion $1 \mathrm{~b} \times 0.8=40$ billion $\mathrm{lb}$. The total weight of carburized parts is 40 billion $\mathrm{lb} \times 0.2=8$ billion lb/year. The total weight of parts for which the carburization cycle can be eliminated is 8 billion $\mathrm{lb} \times 0.1=0.8$ billion $\mathrm{lb}$. Thus, the energy savings would be (1,500-750) Btu/lb x 0.8 billion $\mathrm{lb}=600$ billion Btu. The savings due to the process cost reduction would be $\$ 0.25 / \mathrm{lb} \times 0.8$ billion $\mathrm{lb}=\$ 0.2$ billion $=\$ 200$ million per year.

To evaluate the increase of the heat-treating furnace productivity, we considered a batch-type furnace and made the following assumptions:

$\Rightarrow$ Average duration of the carburization cycle is 10 hours

$\Rightarrow$ Average duration of the heating cycle for quenching with no carburization is 2 hours

$\Rightarrow$ Average duration of the quenching cycle in oil is 45 minutes

$\Rightarrow$ Average duration of the IQ cycle is 5 minutes

The average duration of the carburization cycle with the following quenching cycle is $10 \mathrm{hr} 45$ $\mathrm{min}$, while the average duration of the IQ cycle with no carburization is $2 \mathrm{hr} 5 \mathrm{~min}$. Thus, the furnace productivity would increase by $10 \mathrm{hr} 45 \mathrm{~min} / 2 \mathrm{hr} 5 \mathrm{~min}=5.16$ times.

Table 13 summarizes the above assumptions. Table 14 shows the annual savings for the industry. As seen from these data, annual savings will be up to $\$ 600,000,000$ when the IQ process is fully commercialized. An expected reduction of furnace $\mathrm{CO}_{2}$ emissions is 148,000 ton per year for the whole Heat-Treating Industry.

Table 13 Assumption Made for Evaluation of Annual Savings for Heat Treating Industry

\begin{tabular}{|l|l|}
\hline \multicolumn{1}{|c|}{ Parameter } & \multicolumn{1}{c|}{ Value } \\
\hline Steel parts processed per year & 40 billion $\mathrm{lb}$ \\
\hline Percent of carburized parts & $20 \%$ or 8 billion \\
\hline Percent of currently carburized parts for which: & \\
- carburization cycle can be fully eliminated & $10 \%$ or 4 billion $\mathrm{lb}$ \\
- carburization cycle can reduced by $30 \%$ & $50 \%$ or 20 billion $\mathrm{lb}$ \\
\hline Energy required by carburization process & $1,500 \mathrm{Btu} / \mathrm{lb}$ \\
\hline Energy required for through hardening process & $750 \mathrm{Btu} / \mathrm{lb}$ \\
\hline $\begin{array}{l}\text { Cost difference between carburization/hardening } \\
\text { process and through hardening process }\end{array}$ & 25 cent/lb \\
\hline
\end{tabular}


Table 14 Annual Savings for Heat Treating Industry

\begin{tabular}{|c|c|c|}
\hline Parameter & $\begin{array}{l}\text { Amount of } \\
\text { Parts, } \\
\text { Billion lb } \\
\end{array}$ & Value \\
\hline $\begin{array}{l}\text { Energy savings: } \\
\text { - Full elimination of carburization cycle } \\
\text { - Reduction of carburization cycle by } 30 \% \\
\text { Total: }\end{array}$ & $\begin{array}{c}4 \\
20\end{array}$ & $\begin{array}{l}600 \text { billion Btu } \\
1,200 \text { billion Btu } \\
1,800 \text { billion Btu* }\end{array}$ \\
\hline $\begin{array}{l}\text { Heat treating process cost savings: } \\
\text { - Full elimination of carburization cycle } \\
\text { - Reduction of carburization cycle by } 30 \%\end{array}$ & $\begin{array}{c}4 \\
20 \\
\end{array}$ & $\begin{array}{l}\$ 200,000,000 \\
\$ 400,000,000\end{array}$ \\
\hline $\begin{array}{l}\text { Reduction of furnace } \mathrm{CO}_{2} \text { emissions: } \\
\text { - Full elimination of carburization cycle } \\
\text { - Reduction of carburization cycle by } 30 \%\end{array}$ & $\begin{array}{c}4 \\
20\end{array}$ & $\begin{array}{l}\mathrm{CO}_{2}-92,000 \text { ton } \\
\mathrm{CO}_{2}-56,000 \text { ton }\end{array}$ \\
\hline
\end{tabular}

When calculating the emission reduction, we took into account the following considerations. As known, 1,000 Btu of energy is released when burning one cubic foot of natural gas. On the other hand, burning of one cubic foot of natural gas generates $0.12 \mathrm{lb}$ of carbon dioxide $\left(\mathrm{CO}_{2}\right)$. Thus the saving of 600 billion Btu of energy (or 0.6 billion cubic feet of natural gas) due to elimination of the carburization cycle will reduce the $\mathrm{CO}_{2}$ emissions by 0.072 billion $\mathrm{lb}$ or about 36,000 tons annually. Additional reduction of furnace emissions will take place due to the less use of endothermic gas required for the carburization process. The use of endothermic gas is about $6 \mathrm{ft}^{3}$ per $1 \mathrm{lb}$. of the load being carburized. $20 \%$ of the endothermic gas is carbon monoxide (CO) that burns in the vent creating carbon dioxide. The amount of carbon dioxide created by endothermic gas is about $0.14 \mathrm{lbs}$ per $\mathrm{lb}$. of the furnace load. Thus, elimination of the carburization cycle will reduce the amount of generated carbon dioxide by $0.14 \mathrm{lbs} / \mathrm{lb}$ times 0.8 billion $\mathrm{lb}=0.112$ billion lb. or 56,000 tons per year. The total reduction of the carbon dioxide emissions will be about 92,000 tons per year.

Note also, that the substitution of oil will reduce the impact on the environment by eliminating washing of the oil from the parts after quenching and by eliminating burning of the oil from the part surface during the tempering process following quenching.

\subsection{Savings Due to Reduction of Part Weight.}

As an example, we considered one steel part - an automotive coil spring. Over the last several years, IQ Technologies, Inc. together with a major automotive part supplier have conducted an extensive study on the application of the IQ process to this part. We conducted IQ trials for a number of coil springs of different sizes and types of steel. The coil spring manufacturer conducted an extensive evaluation of the performance of the intensively quenched coil springs and compared them to the same standard oil-quenched parts. The results showed that intensively quenched coil springs could be made from a thinner wire compared to standard oil-quenched springs for the same part performance characteristics. A coil spring weight reduction of $10 \%$ can be achieved by using the IQ process. Table 15 summarizes the results of the economical evaluation of the annual savings for one automotive coil spring production line. 
Table 15 Annual Savings For One Automotive Coil Spring Production Line

\begin{tabular}{|l|l|}
\hline \multicolumn{1}{|c|}{ Parameter } & \multicolumn{1}{|c|}{ Value* $^{*}$} \\
\hline Average coil spring weight & $10 \mathrm{lb}$ \\
\hline Weight reduction due to use of IQ process & $10 \%$ \\
\hline Annual coil spring production by one line & $3,000,000$ \\
\hline Coil spring material cost & 35 cent/lb \\
\hline Annual saving in material cost & $\$ 1,050,000$ \\
\hline Annual energy savings & $\$ 11,800$ or $\quad 15$ billion Btu \\
\hline
\end{tabular}

Note: *) Provided by a coil spring manufacturer

As seen from the table, annual savings in material cost only for only one automotive coil spring production line is more than a million dollars while the energy savings is about 15 billion Btu. Note that the above automotive part supplier has 8 coil spring production lines. Thus the full introduction of the IQ process in the plant heat-treating practice will result in $\$ 8,400,000$ of material savings and 120 billion Btu of energy savings.

To determine potential savings for the whole USA Heat Treating industry due to the part weight reduction, lets assume conservatively that the weight of $10 \%$ of all heat-treated steel parts (or 4 billion lb, see Section 7.1.2 above) can be reduced by 5\%. Thus, the total material savings would be 4 billion $\mathrm{lb} \times 0.05=0.2$ billion $\mathrm{lb}$. Assume also, that $20 \%$ of these parts are carburized and quenched and the remaining parts are just hardened through (see Section 7.1.2 above). Then, the annual savings in energy and cost for the USA Heat Treating industry will be the following:

$\Rightarrow$ Energy savings:

$\circ$ for carburized parts -0.2 billion $\times 0.2 \times 1,500 \mathrm{Btu}=60$ billion Btu

$\circ$ for hardened through parts -0.2 billion $\times 0.8 \times 750 \mathrm{Btu}=120$ billion Btu

$\Rightarrow$ Cost savings assuming an average steel cost of $\$ 0.35$ per pond: 0.2 billion $\times \$ 0.35=$ $\$ 70,000,000$.

Note also that in addition to the above there will be also energy and cost savings for the Steel industry due to not producing the 0.2 billion $\mathrm{lb}$ of steel.

\subsection{Summary of Benefits Provided by IQ Process}

Table 16 summarizes the economic, energy and environmental benefits that could be realized by using the IQ technology when it is widely commercialized throughout the USA Heat Treating Industry.

Table 16. Summary of Economic, Energy and Environmental IQ Process Benefits for USA Heat Treating Industry

\begin{tabular}{|l|l|}
\hline \multicolumn{1}{|c|}{ IQ Process Benefit } & \multicolumn{1}{|c|}{ Annual Benefit for USA Heat Treating Industry } \\
\hline $\begin{array}{l}\text { Full elimination or 30\% reduction of } \\
\text { the carburization cycle }\end{array}$ & $\begin{array}{l}\text { Savings of } 1,800 \text { billion Btu of energy } \\
\text { Cost reduction by } \$ 600,000,000 \\
\text { Reduction of CO2 emissions by } 148,000 \text { ton }\end{array}$ \\
\hline Part weight reduction by 5\% & $\begin{array}{l}\text { Savings in material cost of } \$ 70,000,000 \\
\text { Savings of } 180 \text { billion Btu of energy }\end{array}$ \\
\hline
\end{tabular}




\section{Conclusions}

To fulfill the project goals, the project team has successfully completed the following work over the course of this project:

- IQT performed a number of IQ demonstrations for a variety of steel products made of different tool steels as well as of alloy and plain carbon steels. A total of 33 manufacturers of steel products provided steel parts for IQ trails. IQT conducted IQ demonstrations for 34 different steel parts. We have proved that an intensive quenching process is an effective and environmentally friendly alternative way of quenching steel parts providing steel products with superior mechanical properties and performance characteristics.

- Our customers tested intensively quenched parts in actual field conditions to evaluate the product service life and performance improvement. The data obtained from the field showed significant improvement in part performance characteristics. For example, the service life of cold-work punches made of S5 shock-resisting steel improved by two to eight times. Aluminum extrusion dies made of hot work $\mathrm{H} 13$ steel outperformed the standard dies by at least 50\%. Dies made of plain carbon 1045 steel and used for pellet manufacturing outperformed the standard dies by more than $100 \%$.

- We proved for a number of parts made of carburized steels that by using the IQ process the carburization cycle can be reduced by $40 \%$ resulting in significant energy savings, in reduction of emissions and in increase of the heat-treating equipment production rate.

- CWRU conducted a material characterization study for a variety of steels to develop a database to support changing/modification of recognized standards for quenching steel parts. The conclusions from this study are as following:

- For a given type of steel of the same section size, the intensively quenched steel specimens generally develop a higher strength, and, at the same time, a higher ductility than the steel samples quenched in oil.

- The impact properties obtained from intensively quenched steels are generally superior to the impact properties from oil-quenched steels. While the strength level varies depending on the section size and type of steel, because of the rapid cooling rate obtained at the surface of the part and the finer microstructure obtained throughout the part section, the intensively quenched material does exhibit better mechanical properties than the oil quenched material.

- For carburized grades of steel, the intensive quenching process provides both the higher effective case depth and the greater and deeper residual surface compressive stresses.

- The intensively quenched specimens made of plain carbon steel showed deeper effective case depth and higher residual surface compressive stresses than the specimens made of alloy carburized grades and quenched in oil.

- For through hardened steel test rollers, the compressive residual stresses below the surface were the highest for the samples given the high-velocity intensive quench process. These residual stresses extended under the surface to a depth of 2.5 to $2.9 \mathrm{~mm}$.

- Akron Steel Treating Co. improved capabilities of the existing IQ equipment installed at its facilities.

- We introduced the IQ process in heat treat practices of three commercial heat-treating shops: Akron Steel Treating Co., Summit Heat Treating Co. and Euclid Heat Treating Co.

- IQT conducted a series of IQ workshops, published seven technical papers and participated in ASM 2005 Heat Treating Society conference and exposition and in 2003 Furnace North America Show. 
- IQT established a "Center for Intensive Quenching" at the AST facilities. The 4,000 square feet Center includes a high-velocity single part quenching IQ unit equipped with a neutral salt bath furnace and a high-temperature, electric-fired, atmosphere, box furnace; a 1,900 gallon IQ system with a $\varnothing 24 " x 24 "$ atmosphere pit furnace and a load transfer mechanism; and a shaker hearth furnace equipped with an IQ water tank and with a chiller to maintain the required water temperature.

- While establishing the Center for Intensive Quenching was a great step towards the acceleration of the IQ commercialization process, we are still facing the following barriers in the full introduction of the IQ process in the USA Heat-Treating industry:

- No industrial (captive) installations of IQ systems in the USA

- Lack of steel properties database on many steel types - database is needed for conducting computer simulations that will optimize the compressive stresses while minimizing distortion.

- Limited capabilities in education/promotion of the IQ technology - an intensive quenching process is not currently taught in any metallurgical curriculum in the USA

- Need to develop new standards for heat treatment of steel parts that include the use of the IQ methods. 


\section{Recommendations}

To introduce widely an intensive quenching technology into the heat-treating practice, first of all, we recommend evaluating the IQ processes by steel part manufacturers having captive heattreating shops. In this case, both the part designers and heat treaters will benefit from the IQ method. The part designers will be able to reduce the part weight, to obtain greater power density, or to save money by using less alloy steel. While the heat treaters will be able to realize other IQ process benefits such as improved heat-treating equipment production rate, reduced heat treatment process cost, improved environment by elimination of oil, etc. Planting such "seeds" in big U.S. companies (such as Dana Corp., ArvinMeritor, Inc., Delphi Co., Timken Co., etc.) and the growth of these seeds is extremely important since the large manufacturers have hundreds of plants where this technology can be effectively used, saving millions of gallons of quench oil per year and reducing or eliminating energy intensive carburization cycles.

Secondly, to involve more commercial heat-treating shops, we recommend local ASM Chapters to request the IQ Technologies, Inc. to conduct IQ workshops for the local heat treaters and steel part manufacturers. Conducting such workshops will help to educate the wider metallurgical community on the many proven benefits of intensive water quenching, as well as, to reduce the time lag between the first "demonstration" phase and the actual adoption of intensive quenching practices into production.

We recommend to all suppliers of steel products to the Department of Defense to consider the IQ technology since it can by effectively applied to a number of steel components for advanced weapon systems making this systems stronger, lighter, less expensive and yet more durable. Preliminary results obtained for the gear and bearing products under the current projects with the US Army and Air Force are very encouraging.

For companies that expressed an interest in the IQ technology, we recommend the following procedure for evaluating and for further introduction of the IQ methods:

- Specify parts that could benefit from the IQ process

- Provide IQT with all technical information regarding the specified parts needed for the further evaluation by IQT whether the IQ methods are applicable to the selected parts

- Provide IQT with a set of test parts for the IQ demonstration/validation in the IQT's Center for Intensive Quenching in Akron, Ohio or in production IQ equipment installed at the Akron Steel Treating Co. and Euclid Heat Treating Co.

- If the IQ trial results are favorable, conduct an economical evaluation of the benefits of the IQ process for your specific production conditions

- If the economic outcome is promising, order proper IQ equipment from IQT or from the AFC-Holcroft, Inc. of Wixom, Michigan, an IQT's licensee and buy a license from IQT to use the IQ process for the specified parts. The customer will also have an option to outsource the above Akron Steel Treating and Euclid Heat Treating companies for intensive quenching of the parts. 


\section{References}

1. Kobasko, N. I., "Intensive Steel Quenching Methods", Handbook "Theory and Technology of Quenching”, Springer-Vertag, 1992.

2. Kobasko, N. I., "Basics of Intensive Quenching", Advance Material and Processes, September 1995.

3. Kobasko, N. I., "Part II: Basics of Intensive Quenching", Advance Material and Processes, August 1996.

4. Kobasko, N. I., "Part III: Basics of Intensive Quenching", Advance Material and Processes, February 1998.

5. Kobasko, N. I., "Part IV: Basics of Intensive Quenching", Advance Material and Processes, December 1999.

6. Aronov, M. A., Kobasko, N. I., Powell, J.A., Wallace, and J. F., Schwam, D., "Experimental Validation of The Intensive Quenching Technology for Steel Parts", Proceedings of The $18^{\text {th }}$ ASM Heat Treating Conference, Chicago, Illinois, 1998.

7. Aronov, M. A., Kobasko, N. I., Powell, J.A., Wallace, et al., "Experimental Study of Intensive Quenching of Punches", Proceedings of $19^{\text {th }}$ ASM Heat Treating Conference, Cincinnati, Ohio, 1999.

8. Aronov, M.A., Kobasko, N.I., Powell, J.A., John Young, "Practical Application of Intensive Quenching Technology for Steel Parts and Real Time Quench Tank Mapping", Proceedings of $19^{\text {th }}$ ASM Heat Treating Conference, Cincinnati, Ohio, 1999.

9. Aronov, M. A., Kobasko, N. I., Powell, J.A., Wallace, and J. F., Schwam, D., "Practical Application of the Intensive Quenching Technology for Steel Parts," Industrial Heating Magazine, April 1999.

10. Aronov, M.A., Kobasko, N.I., Powell, J.A., "Practical Application of Intensive Quenching Process for Steel Parts", Proceedings of $20^{\text {th }}$ ASM Heat Treating Conference, St. Louse, Missouri, 2000.

11. Aronov, M.A., Kobasko, N.I., Powell, J.A., "Practical Application of Intensive Quenching Process for Steel Parts", Proceedings of $12^{\text {th }}$ IFHTSE Congress, Melbourne, Australia, November 2000.

12. Aronov, M. A., Kobasko, N. I., Powell, J.A., Wallace, and J. F., Schwam, D., "Practical Application of the Intensive Quenching Technology for Steel Parts", Journal of Heat Treatment of Metals, England, Volume 1, 2000.

13. Aronov, M.A., Kobasko, N.I., Powell, J.A., "Application of Intensive Quenching Methods for Steel Parts", Proceedings of $21^{\text {st }}$ ASM Heat Treating Conference, Indianapolis, Indiana, November 2001.

14. Aronov, M.A., Kobasko, N.I., Powell, J.A., "Application of Intensive Quenching Technology for Steel Parts", Proceedings of SAE Heat Treating Conference, Las Vegas, Nevada, 2002.

15. Aronov, M.A., Kobasko, N.I., Powell, J.A., "Review of Practical Application of Intensive Quenching Methods for Steel Parts", Proceedings of $13^{\text {th }}$ IFHTSE Congress, Columbus, Ohio, October 2002.

16. Aronov, M.A., Kobasko, N.I., Powell, J.A., "Intensive Quenching Technology for Tool Steels", Proceedings of $13^{\text {th }}$ IFHTSE Congress, Columbus, Ohio, October 2002.

17. Aronov, M.A., Kobasko, N.I., Powell, J.A., Pratap Ghorpade, D. Gopal, "Application of Intensive Quenching Processes for Carburized Parts", Proceedings of $22^{\text {nd }}$ ASM Heat Treating Conference, Indianapolis, Indiana, 2003.

18. Lipniki, D.V., "Production Intensive Quenching System", Presentation to $22^{\text {nd }}$ ASM Heat Treating Conference, Indianapolis, Indiana, 2003. 
19. M.P. Mukhina, N.I. Kobasko and L.V. Gordejeva, "Hardening of Structural Steels in Chloride Quenching Media", Metallovedenie I Termicheskya Obrabotka Metallov", Vol. 9, 1989, p.32-36 (in Russian).

20. Aronov, M.A., Powell, J.A., "IQ for Steel Parts", Journal of Materials World, England, November 2003.

21. Aronov, M. A., Kobasko, N. I., Powell, J.A., Wallace, Y. Zhu, "Effect of Intensive Quenching on Mechanical Properties of Carbon and Alloy Steels", Proceedings of $23^{\text {rd }}$ ASM Heat Treating Conference, Pittsburgh, Pennsylvania, 2005.

22. Aronov, M. A., Kobasko, N. I., Powell, Hubbard, C., Tang, F., "Intensively Quenched Rod Residual Stress Mapping", Proceedings of $23^{\text {rd }}$ ASM Heat Treating Conference,

Pittsburgh, Pennsylvania, 2005 